\title{
Les enjeux de l'urbanisme post-catastrophe dans le Japon du Nord-Est, 10 ans après le tsunami du 11 mars 2011
}

東日本大震炎秝らの復興にみる現代の都市・地域計画の課題

The Challenges of Urban and Regional Planning in the Wake of the 11 March Disaster in North-East Japan

\section{Satoshi Miyake}

Traducteur : Rémi Scoccimarro

\section{(2) OpenEdition}

\section{Journals}

Édition électronique

URL : https://journals.openedition.org/ebisu/5759

DOI : 10.4000/ebisu.5759

ISSN : 2189-1893

Éditeur

Institut français de recherche sur le Japon à la Maison franco-japonaise (UMIFRE 19 MEAE-CNRS)

\section{Édition imprimée}

Date de publication : 1 novembre 2021

Pagination : 93-135

ISSN : 1340-3656

\section{Référence électronique}

Satoshi Miyake, «Les enjeux de l'urbanisme post-catastrophe dans le Japon du Nord-Est, 10 ans après le tsunami du 11 mars 2011 », Ebisu [En ligne], 58 | 2021, mis en ligne le 01 novembre 2021, consulté le 13 avril 2022. URL : http://journals.openedition.org/ebisu/5759 ; DOI : https://doi.org/ 10.4000/ebisu.5759 


\section{Les enjeux de l'urbanisme post-catastrophe dans le Japon du Nord-Est, 10 ans après le tsunami du 11 mars 2011}

MiYaKe Satoshi

東日本大震災からの復興にみる現代の都市・地域計画の課題

三宅諭

The Challenges of Urban and Regional Planning in the Wake of the 11 March Disaster in North-East Japan

MiYAKe Satoshi

\begin{abstract}
\ Mots-clés : grand séisme du Japon de l'Est, tsunami, reconstruction, planification urbaine et régionale, société en déclin démographique
\end{abstract}

L'auteur: Miyake Satoshi est maître de conférences à la faculté d'agriculture de l'université d'Iwate. Ses recherches portent sur la planification urbaine et régionale. Après le grand séisme du Japon de l'Est, il a participé à la reconstruction de plusieurs municipalités placées sous la supervision directe du ministère de l'Aménagement du territoire, des Infrastructures, des Transports et du Tourisme.

Résumé : Dix ans se sont écoulés depuis la catastrophe du 11 mars dans le Japon de l'Est, une région déjà en déclin démographique. Cet article résume les facteurs qui ont conduit à l'installation des populations dans les zones basses, puis leur retour généralisé vers des terrains plus élevés lors de la reconstruction post-tsunami. Nous traitons également des mérites et démérites de ces plans de reconstruction, basés sur les principes de l'urbanisme du $\mathrm{xx}^{\mathrm{e}}$ siècle. Nous analysons les logiques à l'œuvre dans le choix de construction des digues et les raisons pour lesquelles leur hauteur a été fixée sans grandes controverses dans le département d'Iwate. Cela nous conduit à analyser les modalités de relogement et les contraintes posées par le déclin démographique de ces régions. 
フキーワード

東日本大震災、津波、復興、都市・地域計画、 縮減社会

\section{著者}

三宅諭：岩手大学農学部准教授。専門分野は 都市・地域計画。東日本大震災からの復興に あたっては、国土交通省による復興パターン 検討業務直轄調査で、野田村、田野畑村、岩 泉町、山田町の作業監理委員を務めたほか、 複数の市町村の復興支援に関わった。

\section{要旨}

人口減少社会の中で発生した東日本大震災か ら 10 年目を迎える。本稿では、過去の三陸 津波からの復興において高台移転が行われな がら低地部へ戻ってきた要因と、今回の近代 都市計画理論に基づく復興計画の長所と短所 を整理している。また、防潮堤整備に対する 考え方の経緯を踏まえて、今回の防潮堤高さ 設定と岩手県で防潮堤議論が争点とならな かった理由を明らかにしている。さらに、住 宅地整備に焦点を当てて実際の復興事業のパ ターンとその要因を整理している。その上で、 縮減社会における都市・地域計画に求められ る課題を提起している。

a region already faced with a declining population. This article outlines the factors that led to populations being resettled in low-lying areas, and their collective return to higher ground during post-tsunami reconstruction. We also address the merits and demerits of these reconstruction plans based on the principles of 20th century urbanism. We analyse the logic behind the decision to build seawalls, and the reasons why their height was set with little controversy in the Iwate Prefecture. From there we analyse the conditions for rehousing, and the constraints imposed by the declining population in these regions.

Abstract: Ten years have passed since the disaster of 11 March in East Japan, 


\section{Les enjeux de l'urbanisme post-catastrophe dans le Japon du Nord-Est, 10 ans après le tsunami du 11 mars 2011}

MIYAKE Satoshi*

\section{Introduction}

Dix ans se sont écoulés depuis le Grand désastre du Japon de l'Est ${ }^{1}$, qualifié alors de catastrophe d'une ampleur et d'une portée sans précédent. De nombreuses vies ont été perdues lors du tsunami qui a frappé la côte Pacifique du Tōhoku. Au moment de la catastrophe, on estimait qu'il faudrait plus de 10 ans pour s'en remettre. Mais grâce à l'implication forte du gouvernement central, par le biais des programmes de subventions pour la reconstruction, la majeure partie des municipalités touchées, à l'exception de celles du département de Fukushima, ont presque terminé leurs plans d'aménagement post-catastrophe et la restauration de leurs infrastructures. Aujourd'hui, la plupart des logements temporaires du Sanriku ont été démontés. La reconstruction des digues de protection et du réseau routier n'est pas totalement terminée, mais pour le reste, infrastructures et logements, tout a progressé bien plus rapidement que prévu.

À la suite de cette catastrophe, la prise en compte de l'aléa de tsunami a conduit à la réévaluation de risques sismiques dans les fosses de Tōkai et de Tōnankai. Cela a entraîné la mise en place de travaux d'anticipation de la

1. Higashi Nihon daishinsai (mot à mot " Grand désastre du Japon de l'est »), le séisme et le tsunami qui ont frappé le Nord-Est du Japon le vendredi 11 mars 2011. (N.D.T.).

* Maître de conférences à la faculté d'agriculture de l'université d'Iwate. 
reconstruction post-catastrophe pour ces territoires. Avec la mise à jour des plans de réaction en cas de crise, cela pourrait permettre un rétablissement plus rapide lors d'aléa majeur dans ces régions. Dans ce cadre, il est nécessaire d'examiner les modalités de rétablissement après une catastrophe de tsunami de grande ampleur, telle que celle du 11 mars 2011, et d'identifier les problèmes imprévus.

L'objectif de cet article est d'identifier les problèmes d'aménagement du territoire rencontrés lors de la reconstruction qui a suivi la catastrophe du 11 mars 2011. En nous appuyant sur le cas du département d'Iwate, nous espérons pouvoir nourrir les réflexions sur les reconstructions post-catastrophe.

Depuis le 11 mars 2011, de nombreuses recherches ont été publiées dans le domaine de l'urbanisme et de l'aménagement post-catastrophe. Concernant la reconstruction, on peut citer Kondō (2015) sur l'avancement effectif des plans de relocalisation des logements, Matsumoto et Ubamura (2015) sur le système de définition des zones à risque et les questions liées à l'usage des sols. Hagiwara et Kubota (2018) ont eux comparé les objectifs des plans et les résultats sur le terrain de projets destinés aux villages de pêcheurs du Sanriku. Dans une étude axée sur les souhaits des résidents pour les plans de reconstruction, Araki et Akita (2017) se sont intéressés à l'impact des modèles résidentiels en vigueur et leur évolution dans l'espace et dans le temps. Yamanaka et al. (2018) ont, eux, explicité les enjeux de la reconstruction des zones résidentielles dans les petits villages de pêcheurs, en se basant sur les caractéristiques des ménages touchés par la catastrophe et leurs souhaits concernant la reconstruction de leurs habitations. Les travaux de Hashimoto (2012) se concentrent sur les modalités de l'usage du sol dans les zones touchées par le tsunami et les questions de contrôle de la planification, en examinant les problèmes posés par la reconstruction post-séisme.

Sur le plan de l'urbanisme post-catastrophe, Satō discute les idées et les principes qui ont émergé lors des actions de soutien à la reconstruction dans la ville d'Ōfunato (Satō 2012). Nous avons soulevé nous-même diverses questions qui se posent dans le processus de planification, en particulier pour la reconstruction des logements, par le biais de la relocalisation groupée des logements (Miyake 2013). Onoda et al. ont étudié les modalités de la mise en œuvre effective des plans de la reconstruction (Onoda et al. 2015). En ce qui concerne la participation des citoyens aux plans 
de reconstruction, Sonoda et al. ont étudié le fonctionnement des ateliers participatifs organisés dans le cadre de l'élaboration des plans de réaménagement, en particulier la manière dont les décisions des résidents ont été reflétées dans le processus de planification, au sein des comités en charge de l'urbanisme collaboratif (Sonoda et al. 2013). Nous nous sommes aussi concentré sur le projet d'aménagement d'espaces verts dans les zones à risque mené sur six ans dans le village de Noda. Et avec Sonoda, nous avons étudié les aménagements mis en œuvre dans ce cadre à Noda avec les élèves de l'école primaire, du collège et du lycée (Miyake 2018).

Comme on le constate, les rapports et les recherches focalisées sur des domaines précis se sont accumulés, mais aucune étude n’a été menée pour rendre compte d'une vision globale de reconstruction post-catastrophe. Cet article présente les défis auxquels ont été confrontés la planification urbaine et l'aménagement du territoire pendant ces dix ans, en adoptant une vue d'ensemble. Nous nous basons sur nos propres expériences de terrain et sur les résultats de nos recherches, en particulier celles liées à la reconstruction post-tsunami des villages de Noda et de Tanohata, ainsi que des villes d'Iwaizumi et de Yamada dans le département d'Iwate.

\section{La région du Sanriku et son développement avant la catastrophe du 11 mars 2011}

\section{I.1. Le développement du Sanriku}

Les eaux situées au large du Sanriku (fig. 01) sont une zone de confluence des courants Oyashio et Kuroshio, réputées pour leurs richesses halieutiques. Les côtes sont célèbres pour les algues wakame 若布 et konbu 昆布, en raison de la profusion de nutriments. C'est également un lieu favorable à la pêche aux ormeaux et aux oursins, qui se nourrissent d'algues. La majorité des pêcheries côtières du Sanriku sont en aquaculture, en particulier pour le saumon, l'ormeau et l'oursin, ainsi que pour les champs de wakame, de konbu, d'huîtres et de coquilles Saint-Jacques.

Cependant, ce n'est qu'au début de la période moderne que l'industrie de la pêche s'est développée le long de ces côtes. Non seulement l'introduction de la pêche au filet a permis d'accroître les prises et d'augmenter la production halieutique, mais le développement du transport maritime a également eu un rôle important. La possibilité du transport maritime vers 
des régions éloignées comme Edo (Tokyo), la hausse de la demande depuis les centres urbains et l'expansion des prises, ont contribué au développement des villages de pêche établis le long des côtes du Sanriku (Miyake 2014). Auparavant, il y avait peu de commerce avec le reste du Japon et l'accent était mis sur l'autoconsommation. Les voies de transport vers et depuis l'intérieur du pays étaient limitées par le relief des plateaux de Kitakami, et la route principale était celle longeant la côte vers le nord (l'actuelle route 45), le Hamakaidō.

Le Sanriku a régulièrement été dévasté par les tsunamis, dont les derniers en date étaient ceux de Meiji-Sanriku (1896) et de Shōwa-Sanriku (1933). Mais la région a pu se rétablir à chaque fois grâce au soutien de la consommation nationale japonaise. C'est ainsi la demande nationale en produits marins du Sanriku et les investissements en capital dans leur commercialisation qui ont à chaque fois permis la reprise de l'activité dans la région.

\section{2. Le développement des zones côtières}

Avec l'essor du transport maritime, l'importance des ports du Sanriku s'est affirmée. La ville de Miyako (département d'Iwate) est ainsi devenue le port extérieur du clan Nanbu à l'époque Edo et s'est développée, favorisée par son site de havre naturel, en fond de rias², protégé de la houle de l'océan Pacifique. Miyako avait été dévastée une première fois par le tsunami de l'ère Keichō, en 1611, et le plan de la ville lors de sa reconstruction d'alors est devenu peu ou prou celui de la ville actuelle.

2. Les rias sont des vallées côtières étroites et allongées. (N.D.T.) 
Fig. 01

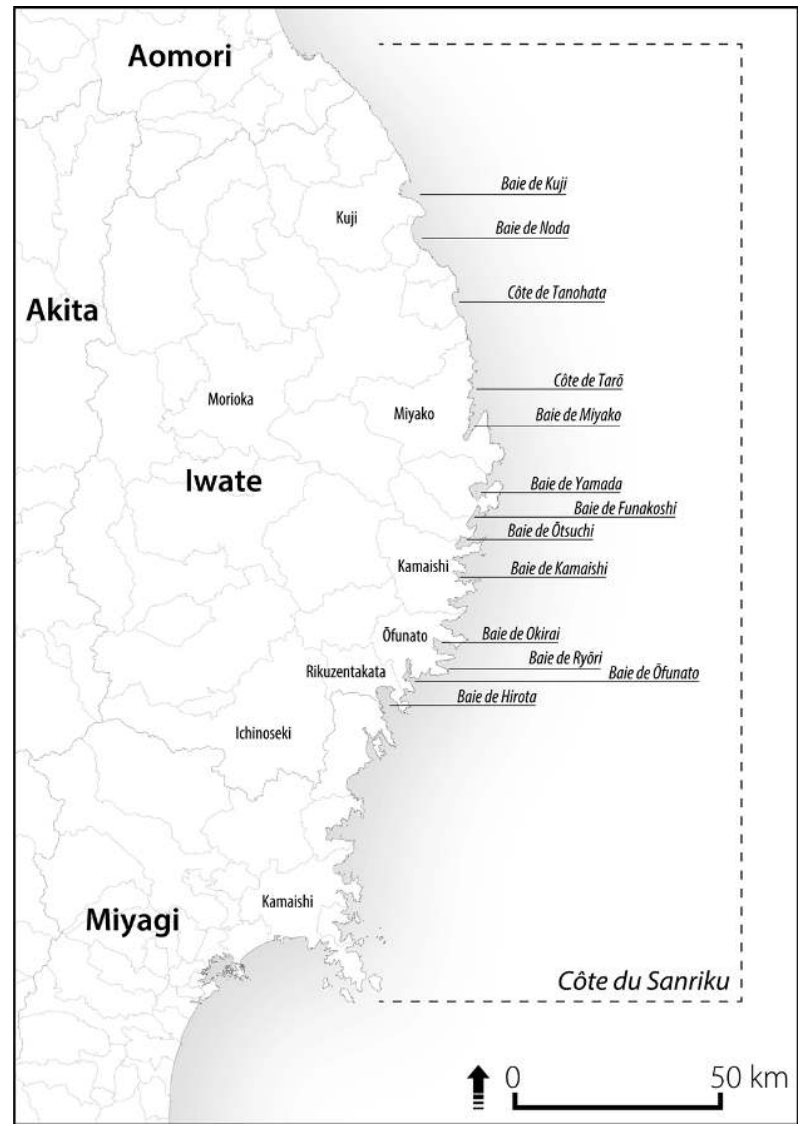

Emplacement de la côte de Sanriku et des principaux ports de pêche.

Réalisation : Miyake (2020).

À l'époque moderne, rivières et côtes basses ont été asséchées en réponse à l'augmentation de la taille des navires et à l'accroissement des marchandises, et la ville a commencé à s'étendre vers la mer. Par la suite, l'ouverture du chemin de fer reliant Miyako à Morioka a développé la fonction commerciale de la ville, alimentant la croissance démographique qui s'est faite elle aussi par l'extension de zones résidentielles vers le littoral (fig. 02). 

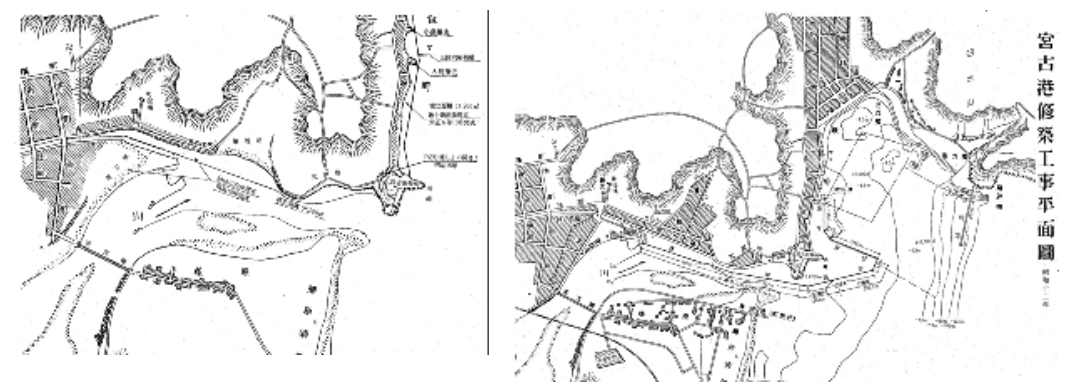

Fig. 02

Plan d'aménagement et de remblaiement du port de Miyako (à gauche : début Meiji, à droite : début Shōwa).

Source : Bureau de la construction de Miyako, ministère des Transports (Un.yushō 運輸省, MoT), 1986.

Cela est vrai pour les villes, mais aussi pour les villages de pêcheurs du Sanriku. Après la guerre, les zones résidentielles se sont étendues avec l'augmentation de la population pendant la Haute croissance. Cependant, les villages de pêcheurs du Sanriku, situés entre des reliefs escarpés et la mer, ne disposaient pas de l'espace nécessaire pour développer ces zones résidentielles. Ils ont donc gagné des terrains sur la mer, en utilisant comme remblais les terres dégagées lors de la construction des routes liées à l'essor de la motorisation. Ces remblais ont permis d'étendre les zones urbaines et de développer plus encore les ports. C'est également la raison pour laquelle des habitations ont été reconstruites dans des zones de basse altitude, alors qu'elles s'étaient déplacées vers des terrains plus élevés après le tsunami de Shōwa-Sanriku. Parallèlement, alors que la construction de la route nationale du Sanriku et des infrastructures progressait, une extension du réseau routier dont cette route nationale est l'artère principale était mise en projet.

Depuis l'ère moderne, la zone côtière du Sanriku s'est donc développée en étendant et en développant les zones urbaines vers le front de mer et les ports. Cependant, dans le contexte actuel de déclin démographique de la région, les grands projets autoroutiers, comme celui de l'autoroute longitudinale de Sanriku, étaient en cours de révision. C'est dans ces conditions que la catastrophe du 11 mars a frappé ces territoires et a coupé en plusieurs points leur réseau routier vieillissant, ce qui les a complétement isolés. 


\section{L'avènement d'une société en déclin démographique et les défis de l'aménagement du territoire}

\section{1. Les différences entre la catastrophe du 11 mars 2011 et les catastrophes naturelles récentes}

La catastrophe du 11 mars est caractérisée par la grande superficie des territoires touchés et par la force du tsunami. De nombreuses catastrophes se sont produites depuis l'ère Heisei, notamment l'éruption du mont UnzenFugendake (1990), le séisme de Hanshin-Awaji (1995), le séisme de Hokkaidō Nansei-Oki (1993) et l'éruption de Miyakejima (2000). Le séisme de Hokkaidō Nansei-Oki a déclenché un tsunami qui a tué plus de 200 personnes sur l'île d'Okushiri. L'éruption du mont Unzen Fugen-dake a duré cinq ans, et pour celle de Miyakejima, il a fallu attendre quatre ans et demi pour que les populations puissent revenir habiter sur l'île. Cependant, aucune de ces catastrophes n'a causé autant de victimes et de destructions que celle du 11 mars 2011, dont la reconstruction a nécessité des aménagements et des travaux de génie civil d'une ampleur inédite (Kikuchi 2017).

Les dommages causés aux moyens de subsistance sont une autre caractéristique de la catastrophe du 11 mars. Dans les zones côtières, l'industrie primaire de la pêche est le fondement de l'économie locale, et de nombreuses personnes occupaient des emplois liés à la pêche et à la transformation du poisson. Ce tsunami était différent des catastrophes classiques car il a emporté non seulement des bâtiments, mais aussi les moyens de subsistance des personnes vivant le long de la côte. Le séisme de Hanshin-Awaji, qui avait frappé le tissu urbain, a causé de nombreux dégâts, mais Kyoto et Osaka ont subi peu de dommages, et de nombreuses personnes ont déclaré que leur lieu de travail était sûr. Dans le cas d'Unzen-Fugendake, bien qu'il $\mathrm{y}$ ait eu des pertes en vies humaines dues au flux pyroclastique de terre et de pierres, de nombreuses personnes travaillaient en ville et l'impact sur leurs moyens de subsistance a été limité. En revanche, si le tsunami d'Okushiri et l'éruption de Miyakejima, qui avait entraîné l'évacuation de toute l'île, sont similaires en termes d'interruption des moyens de subsistance, l'île d'Okushiri a été déclarée en rétablissement complet cinq ans plus tard.

La catastrophe du 11 mars est la première de grande ampleur à se produire dans des communautés où le taux de natalité est en baisse constante, la population vieillissante et la croissance démographique négative. C'est 
l'une des caractéristiques à prendre en compte lors de la reconstruction post-catastrophe.

\section{2. Les différences avec les tsunamis antérieurs du Sanriku}

Les côtes du Sanriku sont des côtes à tsunamis et sont connues comme telles. Les séismes et tsunamis de Meiji-Sanriku en 1896 et de Shōwa-Sanriku en 1933 étaient dans les deux cas nocturnes, causant de nombreuses victimes. Le tsunami du Chili en 1960 a également endommagé des habitations dans les villes d'Ōfunato et de Yamada.

Ainsi, la région du Sanriku a fréquemment souffert de catastrophes causées par des séismes et des tsunamis. Il a été confirmé qu'il y a eu des relocalisations répétées de villages vers des terrains plus élevés mais aussi des relocalisations vers des terrains plus bas. En fait, le "Rapport sur le plan de reconstruction des villes et villages touchés par le tsunami de Sanriku » (Division de l'urbanisme, Secrétariat du ministre de l'Intérieur, 1934), publié après le tsunami du Sanriku de 1933, préconise les mesures suivantes : 1) déplacement des hameaux vers des terrains plus élevés; 2) élévation des terres basses par remblais; 3) construction de digues; 4) construction de brise-lames; 5) reconfiguration de la trame viaire; 6) poldérisation des estrans; 7) construction de routes d'évacuation; 8) implantation de forêts côtières; 9) ouvrage de protection face aux ondes de tempête; 10) politiques de prévention du risque. Nous avons en 2011 mené une enquête auprès des habitants du village de Tanohata sur les raisons du retour dans les zones basses malgré des revendications en faveur de la relocalisation dans les hauteurs. Nous avons appris que la population avait augmenté du fait de l'installation des rapatriés des colonies japonaises après la seconde guerre mondiale. Alors que l'essentiel des déplacements se faisait à pied, installer ces nouveaux habitants sur les hauteurs les auraient placés à trop longue distance de la mer, là où ils travaillaient. Or, ces régions avaient déjà cruellement besoin de la main-d'œuvre qualifiée que ces personnes représentaient. S'établir sur les zones basses a aussi un coût bien plus faible que d'aménager de nouvelles zones résidentielles dans les hauteurs. Dans ces communautés où les moyens de transport étaient encore limités et où l'industrie primaire de la pêche était le cœur de l'activité, vivre à proximité de la mer était ancré dans les habitudes. 
Cependant, nous vivons aujourd'hui dans une société motorisée, même si les distances physiques peuvent être grandes, les temps de trajets sont fortement raccourcis. En outre, dans des sociétés où le nombre de personnes travaillant dans l'industrie primaire diminue et où l'industrie tertiaire devient la principale, il n'est pas nécessaire de vivre enraciné dans la terre. En conséquence, les jeunes quittent la région et il n'est pas surprenant que le taux de natalité soit en baisse et que la population vieillisse. Il est ainsi facile d'imaginer qu'une catastrophe majeure allait accélérer un déclin de la population, car avec les destructions, les seuls éléments qui maintiendraient les populations ensemble seraient les autels bouddhistes, les tombes et le sentiment d'appartenance.

\section{3. Avantages et limites de l'aménagement du territoire et des techniques modernes}

La reconstruction de l'habitat est l'un des principaux enjeux de la reprise après une catastrophe. Pour les Japonais, qui ont un fort attachement à la terre, l'emplacement et la forme de leur maison et de leur terrain sont des préoccupations majeures, et de nombreuses questions se posent lors de la reconstruction post-catastrophe. À la suite du séisme du 11 mars 2011, la question de savoir s’il fallait reconstruire sur les mêmes sites ou déplacer les habitations vers des terrains plus élevés a fait l'objet de nombreux débats. Dans la plupart des cas, on a excavé les reliefs pour aménager, en hauteur, les zones résidentielles destinées aux sinistrés, mêlant pavillons privés et logements publics (saigai kōei jūtaku 災害公営住宅) souvent en collectif. Ces plans sont fondés sur les principes classiques de l'urbanisme dans les sociétés industrielles.

La partie visible de la reconstruction, comme le développement de terrains résidentiels ou l'ouverture de nouvelles routes, donne l'impression d'une restauration du territoire bien avancée. Mais lorsque les gens retournent vivre dans ces nouveaux quartiers, ils se sentent souvent désorientés par les différences avec leur ancienne vie. Par exemple, pour les zones résidentielles situées en hauteur, les habitants ont commencé à regretter de ne pas être près de "la plage qui est fraîche en été, alors que l'intérieur des terres est trop chaud, parce qu'il n'y a pas de brise ». Ils se rappellent combien « c'était un plaisir quotidien de se promener dans la forêt littorale, mais maintenant il n'y a plus d'endroit pour se promener ». À propos de son nouveau logement, une personne nous a confié : "Avant, si vous ouvriez 
une fenêtre, vous étiez juste à côté de la fenêtre du voisin, ce qui était désagréable car il n'y avait pas d'intimité, mais il était facile de se saluer. Aujourd'hui on est plus éloigné et il y a plus d'intimité, mais il est devenu plus difficile de se dire bonjour et de se rencontrer entre voisins ", ou encore "J'avais hâte de vivre dans une nouvelle maison, mais je me sentais mieux dans mon ancienne maison car elle était rafraîchie par la brise. » Passer d'un préfabriqué temporaire à un vrai nouveau logement donne le sentiment qu'un réel pas vers la reconstruction a été fait. Cependant, vivre dans une nouvelle maison ne signifie pas reprendre sa vie d'avant la catastrophe.

Aussi, il est difficile de définir clairement ce qu'est la restauration du territoire, car la seule construction de logements ne ramène pas les habitants à leur vie antérieure. Il faut s'efforcer de reconstruire une vie quotidienne qui sera forcément différente de celle d'avant. La vie quotidienne sans catastrophe évolue aussi, mais en douceur, et les personnes s'adaptent à des changements étalés dans le temps. Toutefois, comme l'indique le terme d'" urgence " qu'on utilise en cas de catastrophe, celle-ci n'est pas un changement sans rupture, mais plutôt une déconnexion majeure entre un avant et un après. Il peut s'agir d'une déconnexion sans grande conséquence lorsqu'elle s'étale sur une longue période, comme un siècle. Mais c'est une déconnexion majeure pour les personnes qui vivent au jour le jour la transformation. C'est particulièrement le cas lorsque les nouvelles zones résidentielles sont éloignées des lieux de vie d'origine, comme c'est le cas avec les plans de relocalisation hors des zones à risque. Cela engendre une coupure forte avec le passé, en termes d'emplacement et aussi de nouveau type d'espace proposé aux habitants délocalisés (Miyake 2018).

La planification urbaine classique se base sur une croissance démographique continue. Elle vise à étendre et créer continuellement de nouvelles zones résidentielles et une amélioration du cadre de vie. Elle permet de garantir une qualité standard et homogène dans tout type de régions.

On peut citer par exemple le projet de réaménagement urbain suivant le grand séisme du Kantō (1923) en se référant aux principes d'urbanisme de l'Allemand Franz Adickes ${ }^{3}$, c'est-à-dire à améliorer le cadre de vie en améliorant les routes, les parcs, la forme des parcelles, tout en réduisant le nombre de procédures pour les propriétaires fonciers. Pour cela, on élargit

3. Urbaniste et maire de Frankfort de 1890 à 1912. (N.D.T.) 
la zone du projet, ce qui permet de créer de nouvelles parcelles, pour les vendre ensuite et réduire les coûts finaux d'aménagement. En outre, pour les complexes résidentiels, on vise à assurer un ensoleillement égal pour chaque parcelle, toutes de tailles égales. La création de ces zones résidentielles, le plus souvent suburbaines, entraîne généralement la perte des caractéristiques régionales héritées dans les territoires où elles se déploient. L'avantage de ce type de planification urbaine, généralisée lors de la Haute croissance, est qu'il est ainsi possible de créer des zones résidentielles d'une certaine qualité, en créant de nouveaux terrains, même dans des zones telles que la côte des Rias. En revanche, sur les côtes du Sanriku, où l'on s'attend à ce que la population diminue, ce type d'opération peut entraîner la création de parcelles non-occupées, tout en entraînant des coûts d'entretien importants sur le long terme. Elles conduisent aussi à une perte d'identité régionale du fait de la standardisation qui caractérise ce type de lotissement.

\section{La planification et les principes de la reconstruction post- tsunami dans le département d'Iwate}

Cette partie résume et analyse la situation des projets de reconstruction post-tsunami dans 12 municipalités côtières du département d'Iwate, sur la base d'entretiens et des données recueillies. Comme il est difficile de couvrir tous les projets de reconstruction, nous nous concentrerons sur ceux qui concernent le relogement. En particulier les projets de relocalisation des hameaux détruits, les projets d'amélioration de la prévention des catastrophes parmi des communautés de pêcheurs, le remembrement urbain, les projets de construction de logements publics pour les victimes de la catastrophe et les projets de construction des digues.

\section{1. Concept de digues pour la reconstruction post-11 mars}

Les côtes du Sanriku sont situées à proximité d'une zone de subduction active de la plaque Pacifique où les séismes sont fréquents. Devoir évacuer, de jour comme de nuit, après chaque tremblement de terre, petit ou grand, n'est pas une sinécure pour les habitants de ces régions. De plus, déplacer les zones résidentielles vers les hauteurs, nécessite de trouver des terrains disponibles et de disposer des technologies nécessaires pour excaver les montagnes. Après 
le tsunami de Shōwa-Sanriku en 1933, le bourg de Tarō est représentatif des sites où on a finalement préféré construire une digue, pour vivre de la manière la plus sûre possible, compte tenu des contraintes de terrain, d'argent et de technologie, en abandonnant le plan de relogement sur les hauteurs (Yamashita 2008). Après que le bourg de Tarō a emprunté de l'argent pour commencer à construire sa digue, celle-ci a été prise en charge et financée par le département d'Iwate. Depuis lors, la construction de tels ouvrages de protection portuaire a été encouragée par le département dans le Sanriku. Ainsi, de nombreuses communes étaient dotées d'ouvrages de protection anti-tsunami avant le grand désastre du Japon de l'Est de 2011. Le tableau 01 indique la hauteur d'inondation prévue en cas de tsunami majeur et la hauteur des digues avant la catastrophe pour chacune d'entre elles. On constate que les hauteurs de digue sont, pour beaucoup, inférieures aux hauteurs d'inondation attendues : elles sont basées sur des maximums atteints lors des tsunamis de Shōwa-Sanriku et de Meiji-Sanriku . Or le tsunami du 11 mars 2011 s'est produit alors que la hauteur des digues était en cours de redéfinition, car un séisme au large du département de Miyagi était attendu. En effet, plus de 70 ans s'étaient écoulés depuis le séisme de Shōwa-Sanriku, et il n’y avait pas eu de tsunami majeur depuis environ 50 ans.

Dans le cadre de la reconstruction, la première question qui s'est posée a été la hauteur des digues. La hauteur du tsunami a dépassé les digues alors construites, et la possibilité d'un tsunami plus important ne pouvait être niée. De plus, tant que la hauteur de la digue n'était pas déterminée, on ne pouvait pas se pencher sur la prévision d'inondation pour l'intérieur de la digue (côté ville), et donc revoir les plans d'occupation des sols pour ces villes. Pour faire face à cette situation, le Conseil central de prévention des catastrophes a établi deux niveaux de tsunami et défini une politique de contre-mesures. Le niveau 1 de prévention (L1) part de l'hypothèse d'un tsunami qui se produit une fois tous les 100 ans et vise à l'empêcher grâce à des digues. Le niveau 2 (L2) définit un risque de tsunami d'une occurrence de 1000 ans et vise à réduire les dommages par la prévention au lieu d'essayer de stopper physiquement les vagues avec les digues.

4. On parle bien ici de la hauteur de l'inondation par le tsunami (shinsuidaka 浸水高), pas des vagues en bout de course (sojödaka 遡上高), qui peuvent atteindre $40 \mathrm{~m}$, mais ne provoquent pas d'inondation. (N.D.T.) 
TABLEAU 01

Hauteur du tsunami et hauteur des digues sur les côtes du Sanriku.

\begin{tabular}{|c|c|c|c|c|c|c|}
\hline \multirow[t]{2}{*}{ Site } & \multirow{2}{*}{$\begin{array}{l}\text { Hauteur } \\
\text { du tsu- } \\
\text { nami du } \\
\text { séisme du } \\
11 \text { mars } \\
2011(\mathrm{~m})\end{array}$} & \multicolumn{2}{|c|}{$\begin{array}{c}\text { Caractéristique du } \\
\text { tsunami }\end{array}$} & \multirow{2}{*}{$\begin{array}{l}\text { Hauteur } \\
\text { de digue } \\
\text { adaptée } \\
\text { aux tsu- } \\
\text { namis } \\
\text { antérieurs } \\
(\mathrm{m})\end{array}$} & \multirow{2}{*}{$\begin{array}{l}\text { Hauteur } \\
\text { de digue } \\
\text { avant le } \\
11 \text { mars } \\
2011(\mathrm{~m})\end{array}$} & \multirow{2}{*}{$\begin{array}{c}\text { Hauteur } \\
\text { de digue } \\
\text { L1 }(\mathrm{m})\end{array}$} \\
\hline & & $\begin{array}{l}\text { Dénomi- } \\
\text { nation }\end{array}$ & $\begin{array}{l}\text { Hauteur } \\
(\mathrm{m})\end{array}$ & & & \\
\hline $\begin{array}{c}\text { Côte } \\
\text { Nord de } \\
\text { Kuji }\end{array}$ & 12 & $\begin{array}{l}\text { Shōwa- } \\
\text { Sanriku }\end{array}$ & 5,4 & 6,4 & 12 & 12 \\
\hline $\begin{array}{c}\text { Baie de } \\
\text { Kuji }\end{array}$ & 13,7 & $\begin{array}{l}\text { Shōwa- } \\
\text { Sanriku }\end{array}$ & 5,4 & 6,4 & $7,3-8$ & 8 \\
\hline $\begin{array}{c}\text { Côte Sud } \\
\text { de Kuji }\end{array}$ & 14,5 & $\begin{array}{l}\text { Shōwa- } \\
\text { Sanriku }\end{array}$ & 10,9 & 11,9 & 12 & 12 \\
\hline $\begin{array}{c}\text { Baie de } \\
\text { Noda }\end{array}$ & 21,4 & $\begin{array}{l}\text { Shōwa- } \\
\text { Sanriku }\end{array}$ & 13 & 14 & 12 & 14 \\
\hline $\begin{array}{c}\text { Côte de } \\
\text { Fudai }\end{array}$ & 18,4 & $\begin{array}{l}\text { Shōwa- } \\
\text { Sanriku }\end{array}$ & 13,3 & 14,3 & 15,5 & 15,5 \\
\hline $\begin{array}{l}\text { Côte de } \\
\text { Tanohata }\end{array}$ & 23 & $\begin{array}{l}\text { Shōwa- } \\
\text { Sanriku }\end{array}$ & 12,8 & 13,8 & 14,3 & 14,3 \\
\hline $\begin{array}{c}\text { Côte } \\
\text { d'Iwai- } \\
\text { zumi } \\
\end{array}$ & 20,2 & $\begin{array}{l}\text { Shōwa- } \\
\text { Sanriku }\end{array}$ & 13,7 & 14,7 & $13,3-14.3$ & 14,7 \\
\hline $\begin{array}{c}\text { Côte de } \\
\text { Tarō } \\
\end{array}$ & 16,3 & $\begin{array}{l}\text { Shōwa- } \\
\text { Sanriku }\end{array}$ & 13,7 & 14,7 & $10-13,7$ & 14,7 \\
\hline $\begin{array}{l}\text { Baie de } \\
\text { Miyako }\end{array}$ & 11,6 & $\begin{array}{l}\text { Meiji-San- } \\
\text { riku }\end{array}$ & 9,4 & 10,4 & $8-8,5$ & 10,4 \\
\hline $\begin{array}{c}\text { Côte } \\
\text { d'Omoi }\end{array}$ & 21,8 & $\begin{array}{c}\text { Meiji-San- } \\
\text { riku }\end{array}$ & 13,1 & 14,1 & 10 & 14,1 \\
\hline $\begin{array}{l}\text { Baie de } \\
\text { Yamada }\end{array}$ & 10,9 & $\begin{array}{c}\text { Meiji-San- } \\
\text { riku }\end{array}$ & 8,7 & 9,7 & 6,6 & 9,7 \\
\hline $\begin{array}{c}\text { Baie de } \\
\text { Funakoshi }\end{array}$ & 19 & $\begin{array}{c}\text { Meiji-San- } \\
\text { riku }\end{array}$ & 11,8 & 12,8 & $8,35-8,5$ & 12,8 \\
\hline $\begin{array}{c}\text { Baie } \\
\text { d'Ōtsuchi }\end{array}$ & 15,1 & $\begin{array}{c}\text { Meiji-San- } \\
\text { riku }\end{array}$ & 13,5 & 14,5 & 6,4 & 14,5 \\
\hline $\begin{array}{l}\text { Baie de } \\
\text { Ryoishi }\end{array}$ & 22,6 & $\begin{array}{c}\text { Meiji-San- } \\
\text { riku }\end{array}$ & 9,7 & 10,7 & $6,4-12$ & 12 \\
\hline $\begin{array}{l}\text { Baie de } \\
\text { Kamaishi }\end{array}$ & 10,1 & $\begin{array}{c}\text { Meiji-San- } \\
\text { riku }\end{array}$ & 4,8 & 5,8 & $4-6,1$ & 6,1 \\
\hline $\begin{array}{c}\text { Baie de } \\
\text { Tōni }\end{array}$ & 21 & $\begin{array}{c}\text { Meiji-San- } \\
\text { riku }\end{array}$ & 13,5 & 14,5 & 11,8 & 14,5 \\
\hline
\end{tabular}


Mirake Satoshi ～Les enjeux de l'urbanisme post-catastrophe...

\begin{tabular}{|c|c|c|c|c|c|c|}
\hline \multirow[t]{2}{*}{ Site } & \multirow{2}{*}{$\begin{array}{l}\text { Hauteur } \\
\text { du tsu- } \\
\text { nami du } \\
\text { séisme du } \\
11 \text { mars } \\
2011(\mathrm{~m})\end{array}$} & \multicolumn{2}{|c|}{$\begin{array}{c}\text { Caractéristique du } \\
\text { tsunami }\end{array}$} & \multirow{2}{*}{$\begin{array}{l}\text { Hauteur } \\
\text { de digue } \\
\text { adaptée } \\
\text { aux tsu- } \\
\text { namis } \\
\text { antérieurs } \\
(\mathrm{m})\end{array}$} & \multirow{2}{*}{$\begin{array}{l}\text { Hauteur } \\
\text { de digue } \\
\text { avant le } \\
11 \text { mars } \\
2011(\mathrm{~m})\end{array}$} & \multirow{2}{*}{$\begin{array}{c}\text { Hauteur } \\
\text { de digue } \\
\text { L1 (m) }\end{array}$} \\
\hline & & $\begin{array}{l}\text { Dénomi- } \\
\text { nation }\end{array}$ & $\begin{array}{l}\text { Hauteur } \\
\quad(\mathrm{m})\end{array}$ & & & \\
\hline $\begin{array}{l}\text { Baie de } \\
\text { Yoshi- } \\
\text { hama }\end{array}$ & 17,2 & $\begin{array}{c}\text { Estimé au } \\
\text { large des } \\
\text { côtes de } \\
\text { Miyagi }\end{array}$ & 6,8 & 7,8 & 14,3 & 14,3 \\
\hline $\begin{array}{c}\text { Baie } \\
\text { d'Okirai }\end{array}$ & 16,9 & $\begin{array}{l}\text { Shōwa- } \\
\text { Sanriku }\end{array}$ & 10,5 & 11,5 & 7,9 & 11,5 \\
\hline $\begin{array}{c}\text { Baie de } \\
\text { Ryōri }\end{array}$ & 23,8 & $\begin{array}{l}\text { Estimé au } \\
\text { large des } \\
\text { côtes de } \\
\text { Miyagi }\end{array}$ & 6,3 & 7,3 & 7,9 & 7,9 \\
\hline $\begin{array}{c}\text { Large de } \\
\text { la baie } \\
\text { d'Ōfunato }\end{array}$ & 17,4 & $\begin{array}{l}\text { Shōwa- } \\
\text { Sanriku }\end{array}$ & 13,1 & 14,1 & $7,9-9$ & 14,1 \\
\hline $\begin{array}{c}\text { Baie } \\
\text { d'Ōfunato }\end{array}$ & 10,4 & $\begin{array}{l}\text { Shōwa- } \\
\text { Sanriku }\end{array}$ & 6,2 & 7,2 & $3-3,5$ & 7,2 \\
\hline $\begin{array}{l}\text { Baie } \\
\text { d'Ōno }\end{array}$ & 16,6 & $\begin{array}{l}\text { Shōwa- } \\
\text { Sanriku }\end{array}$ & 11,8 & 12,8 & $4,8-8,5$ & 12,8 \\
\hline $\begin{array}{c}\text { Large de } \\
\text { la baie de } \\
\text { Hirota }\end{array}$ & 15,2 & $\begin{array}{l}\text { Meiji-San- } \\
\text { riku }\end{array}$ & 11,8 & 12,8 & 6,3 & 12,8 \\
\hline $\begin{array}{l}\text { Baie de } \\
\text { Hirota }\end{array}$ & 18,3 & $\begin{array}{c}\text { Estimé au } \\
\text { large des } \\
\text { côtes de } \\
\text { Miyagi }\end{array}$ & 11,5 & 12,5 & $4,95-6,5$ & 12,5 \\
\hline
\end{tabular}

Source : Enquêtes par interview et de la collecte de documents auprès du département d'lwate.

Dans le département d'Iwate, des simulations de tsunami ont été effectuées pour chaque baie afin de déterminer la hauteur maximale des digues qui pourraient être construites. Cette hauteur a été fixée, puis discutée avec les résidents de chaque zone et finalisée (tableau 01). On constate que la plupart des zones côtières ont été construites au niveau L1, ce qui est plus élevé que les hauteurs de digues d'avant le séisme. Sur ces côtes, les digues dépassent presque toutes les $10 \mathrm{~m}$ au-dessus du niveau de la mer. Dans les seules baies de Kuji, Yamada, Kamaishi, Ryōri et Ōfunato, les digues sont 
inférieures à $10 \mathrm{~m}$. Mais Kuji, Kamaishi et Ōfunato sont désormais dotées d'énormes brise-lames en avant de la baie, pour ralentir la force des tsunamis. Par exemple, à Kamaishi, un brise-lames de $990 \mathrm{~m}$ de long au nord et un brise-lames au sud de $670 \mathrm{~m}$ de long ont été construits à l'embouchure de la baie, avec une ouverture de 300 m (fig. 03) entre les deux.

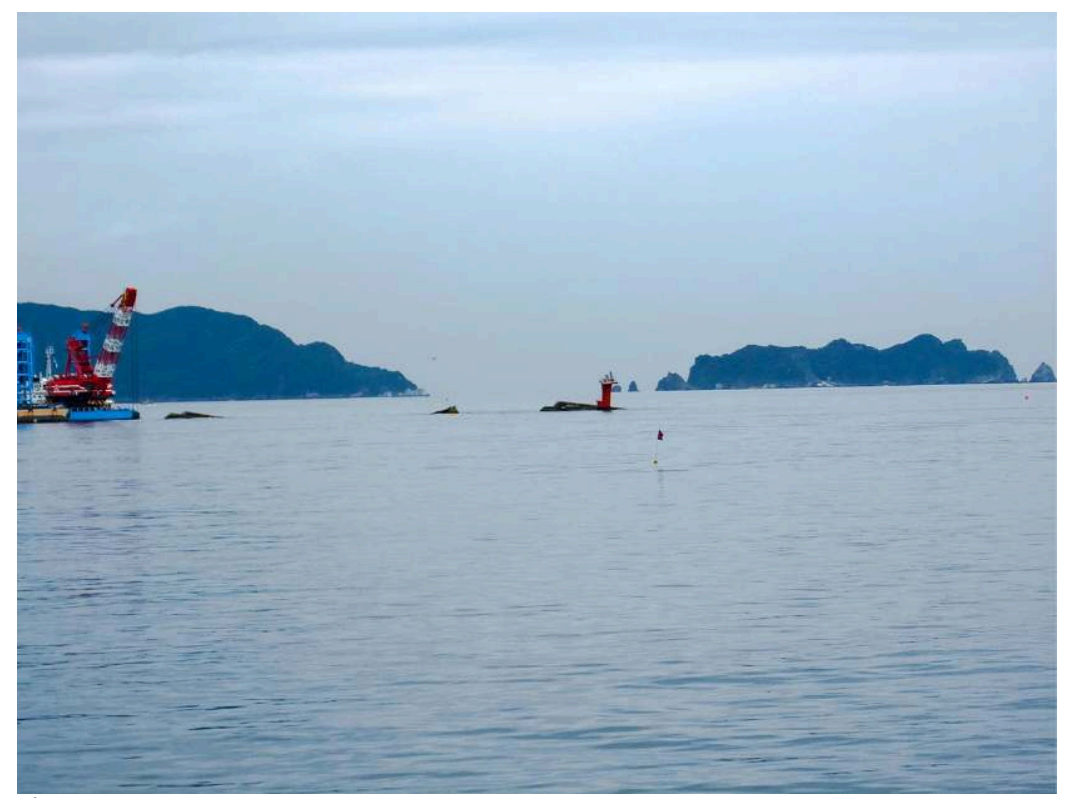

Fig. 03a

Brise-lames de l'embouchure de la baie détruite par le tsunami. 


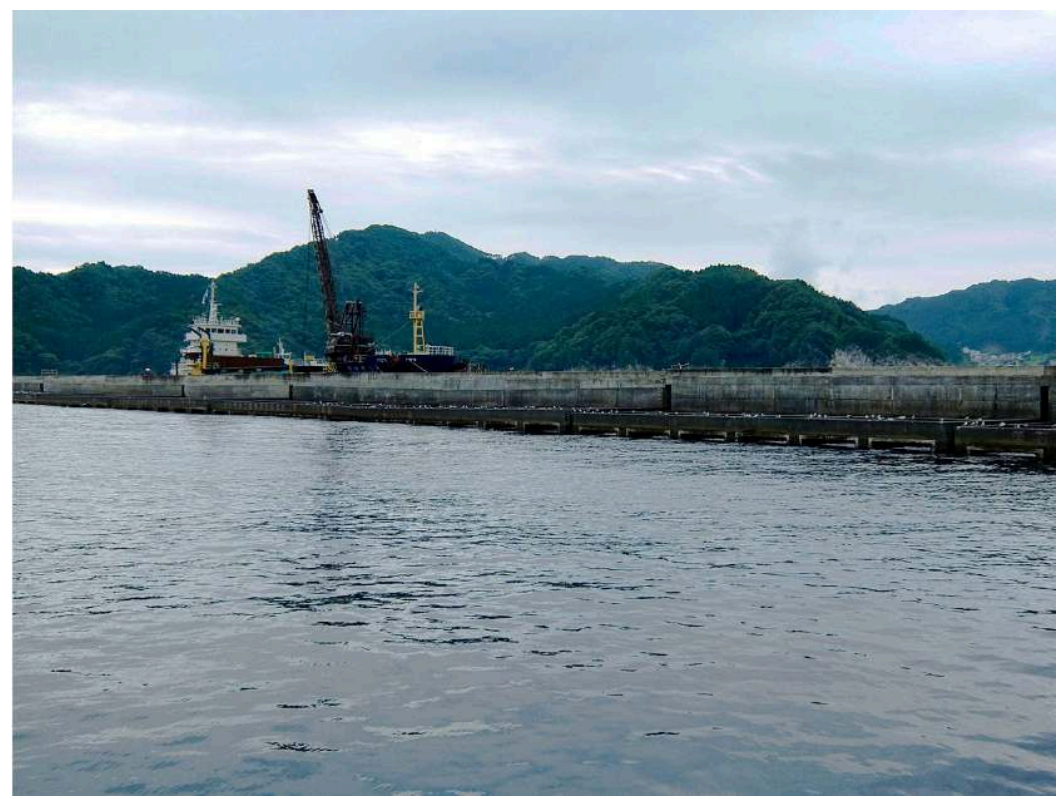

Fig. 03b

Brise-lames de l'embouchure de la baie en cours de reconstruction.

Photos : Miyake Satoshi.

La profondeur des fonds marins est de 50 à $60 \mathrm{~m}$, et la hauteur du briselames à l'embouchure de la baie est de 5,1 m. Lors du tsunami de 2011, il a été vérifié que le brise-lames avait réduit la hauteur du tsunami de $13,7 \mathrm{~m}$ à $8,1 \mathrm{~m}$ et la vitesse d'écoulement de $6,6 \mathrm{~m} / \mathrm{s}$ à $3,0 \mathrm{~m} / \mathrm{s}$. En outre, il a allongé de 6 minutes le temps nécessaire au tsunami pour franchir la zone du briselames et a réduit la hauteur des vagues déferlantes qui n'ont pas excédé $10 \mathrm{~m}$ (ministère de l'Aménagement du territoire, des Infrastructures, des Transports et du Tourisme 2013).

Cependant, il existe de nombreuses zones où la hauteur de digue est plus basse qu'ailleurs sur la côte. Il s'agit, pour la plupart, de zones où il n'y a plus de maisons à protéger du fait de la relocalisation de l'habitat vers les hauteurs ou des zones pour lesquelles les simulations ont déterminé une hauteur de tsunami inférieure au niveau 1. En d'autres termes, des digues de hauteurs inférieures au niveau attendu pour un tsunami de niveau L1 ont été construites en fonction du relogement des résidents vers 
leur hauteurs, mais aussi en fonction du souhait des communautés locales pour des digues moins hautes.

Dans le cas du département d'Iwate, la hauteur du niveau L1 a été fixée comme limite de base et ensuite, c'est aux municipalités qu'a été laissé le soin de trouver un consensus avec les résidents. Finalement, il n’y a pas eu d'opposition significative à la construction des digues de niveau L1. Cela tient à l'histoire de la région et en partie au fait que l'existence des digues était considérée comme acquise. Dans le département de Miyagi, la hauteur des digues a été décidée en amont et les habitants ont été informés des projets dans un deuxième temps. Cela a entrainé des oppositions, d'autant que dans certains cas, on a commencé la construction des digues sans consulter les habitants. Dans la ville de Kesennuma, il était initialement prévu que la digue soit construite à $6,2 \mathrm{~m}$, mais à la suite d'une importante opposition au projet, et d'un délai de quatre ans, elle a finalement été construite à 5,1 m, ce qui correspondait aux exigences du conseil des résidents (Abe 2017).

La principale différence entre le département de Miyagi et celui d'Iwate est que pour ce dernier, ce sont les collectivités locales qui se sont vu confier la recherche d'un consensus avec les résidents. La loi sur le littoral stipule que le département a en charge la gestion des installations côtières, à l'exception des installations portuaires de pêche. Le département est aussi responsable de leur entretien. À Miyagi, l'objectif était une construction rapide des digues et la hauteur, comme les méthodes de construction, ont été décidées en amont, au niveau du département, au prix de frictions locales.

\section{2. Forme et fonction des digues anti-tsunami}

Un autre point de discussion concerne la forme des digues. Elles sont de deux types : soit par un remblai en trapèze, soit un mur droit (fig. 04). La forme est déterminée par les conditions d'utilisation des sols et le souhait de la commune. Étant donné que le type en trapèze, par un remblai, nécessite une grande surface de terrain proportionnellement à sa hauteur, on le choisit pour les zones avec de grandes surfaces planes disponibles ou dans des zones dont les activités ont été déménagées vers les hauteurs. Le type vertical est construit dans les zones côtières étroites et les petits villages de pêcheurs le long des péninsules. Pour des raisons esthétiques, les pentes des digues sont recouvertes d'espaces verts, mais elles sont la plupart du temps 
recouvertes de béton en raison de l'affouillement par les eaux du tsunami et de la destruction des digues par le recul des vagues, constaté en 2011.

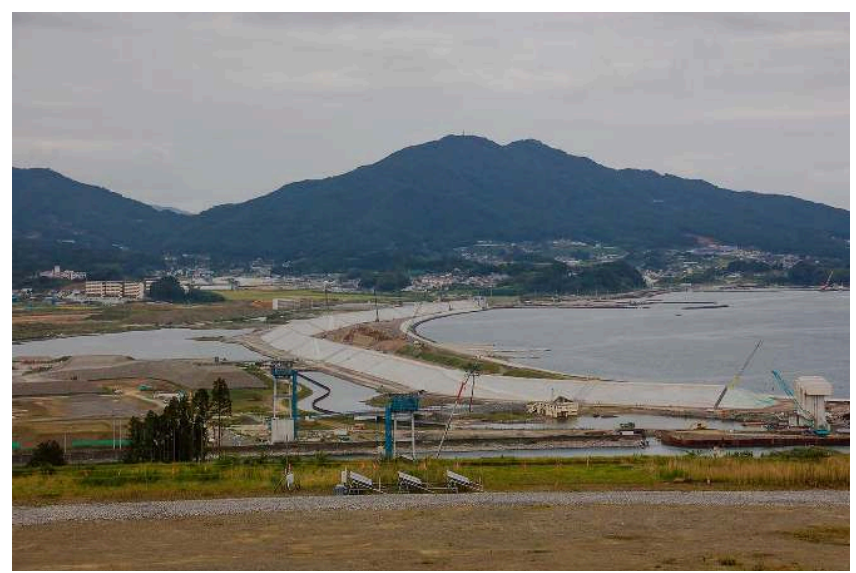

\section{Fig. 04a}

Digue de type remblai.

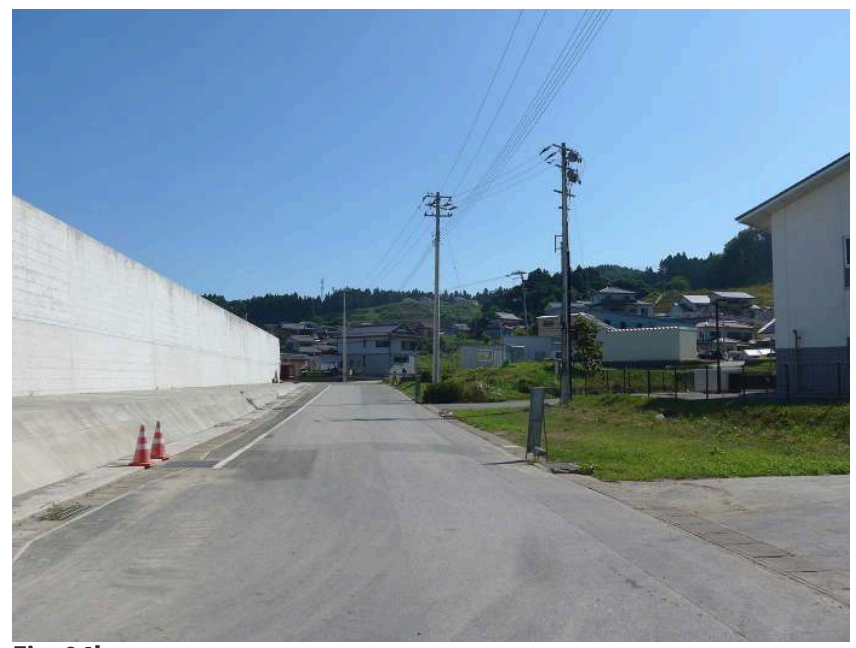

\section{Fig. 04b}

\section{Digue verticale.}

Si le sol plat est large, le type de remblai est possible, mais si le fond est étroit, il y aura moins de sites disponibles et les dommages causés par les inondations augmenteront en cas de 
Le remblai de l'autoroute surélevée Sendai-Ouest a stoppé le tsunami du 11 mars dans la plaine de Sendai, ce qui a fortement réduit l'étendue de la zone d'inondation. Cela a fait naître l'espoir d'un doublement de l'autoroute par une ligne de remblais supplémentaires, pour renforcer la fonction de protection de l'ouvrage, mais le ministère de l'Aménagement du territoire, des Infrastructures, des Transports et du Tourisme a rejeté l'idée de doubler ainsi l'ouvrage. Le doublement de l'autoroute sur un nouveau remblai a été construit sur certains tronçons, mais pas sur l'ensemble de l'infrastructure. Les remblais peuvent être parfois utilisés comme une route, mais il s'agit en général de voie réservée non ouverte à la circulation publique.

Lorsque la digue prend la forme d'un parc, qu'un espace vert a été planté pour protéger la côte, ou que la digue est adjacente à une installation commémorative, la route surélevée constituée par la digue est entretenue de manière à pouvoir être utilisée par le public. Dans le parc commémoratif de la reconstruction du tsunami de Takata-Matsubara, dans la ville de Rikuzentakata, une digue a été construite et l'accès à son sommet sécurisé pour la visite. Un site commémoratif a été installé sur la digue elle-même. La ville d'Ōtsuchi prévoit également d'installer un lieu de prière en haut d'une de ses digues. En principe, aucune autre fonction que celle de la protection n'est pensée pour les digues, mais lors des consultations entre les habitants et les collectivités locales, il y a des demandes pour d'autres usages rendus possibles par ces infrastructures.

\section{3. Critères de sélection des projets de reconstruction}

Si l'on examine la différence entre le Nord et le Sud du Sanriku (tableau 02), la zone côtière du Sud a subi un taux plus élevé d'inondation et davantage de dommages humains et matériels lors du tsunami du 11 mars. Le Sanriku est connu comme une côte de rias, qui s'est formée par subsidence à partir du sud de la ville de Miyako. Au Nord, ce sont des falaises de terrasses soulevées. La partie sud, aux côtes plus découpées, compte quant à elle plus de zones basses en fond de vallée côtière. En revanche, au Nord, on trouve de nombreux villages éparpillés sur la côte au pied des falaises. Les seules zones planes dans la partie nord du Sanriku, sont le bourg de Tarō, dans la commune de Miyako et le village de Noda. Bien que la direction du tsunami soit en partie due au fait que l'épicentre du séisme se trouvait au large 
du département de Miyagi, la topographie locale doit être prise en compte pour expliquer les différences entre le Nord et le Sud dans les choix de type de structure anti-tsunami.

\section{TABLEAU 02}

Projets de reconstruction et schémas de relocalisation dans chaque district.

\begin{tabular}{|c|c|c|c|c|c|c|c|c|c|c|c|c|}
\hline \multirow[b]{2}{*}{ Communa } & \multicolumn{3}{|c|}{ Dommages humans } & \multicolumn{2}{|c|}{ Périmetre dinondation } & \multicolumn{3}{|c|}{ Dommages sur les bătiments } & \multirow[b]{2}{*}{ Typo de surface dótruites } & \multirow{2}{*}{$\begin{array}{l}\text { Fonctonnement } \\
\text { administratif } \\
0: \text { nomale } \\
\Delta: \text { pariel } \\
x: \text { inacif }\end{array}$} & \multirow[b]{2}{*}{ Type de zene hebitbe } & \multirow{2}{*}{$\begin{array}{l}\text { Localisation } \\
\text { des } \\
\text { båimments } \\
\text { administratifs }\end{array}$} \\
\hline & Nors & Disparus & Total & $\begin{array}{c}\text { Surface } \\
\text { inondée } \\
\left(\mathrm{km}^{2}\right)\end{array}$ & $\begin{array}{l}\text { Bất inonóée } \\
\left(\mathrm{km}^{2}\right)\end{array}$ & $\begin{array}{l}\text { Maisons } \\
\text { distruites }\end{array}$ & $\begin{array}{c}\text { Maisons } \\
\text { inordees } \\
\text { parlielement }\end{array}$ & $\begin{array}{l}\text { Batimerts } \\
\text { inordés }\end{array}$ & & & & \\
\hline Hrono & 0 & 0 & 0 & 1 & 9 & 26 & 81 & 187 & Littoral & 0 & $\begin{array}{l}\text { Colines à lintérieur des } \\
\text { terres. }\end{array}$ & houtteurs \\
\hline KuII & 2 & 2 & 4 & 4 & 16 & 278 & 355 & 2257 & Hameau cotter & 0 & Flaine cottere & plaine \\
\hline Noda & 38 & 0 & 38 & 2 & 2 & 479 & 681 & 1126 & Zone urbaine & $\Delta$ & Flaine costere & plaine \\
\hline Fudai & 0 & 1 & 1 & 1 & 1 & 0 & 114 & 157 & Instalatations portuaires & 0 & $\begin{array}{l}\text { Plaine à lintérieur des } \\
\text { lerres }\end{array}$ & plaine \\
\hline Tanohata & 14 & 15 & 29 & 1 & 2 & 270 & 519 & 585 & Hameau côtier & 0 & $\begin{array}{l}\text { Collines a linteriour des } \\
\text { terres }\end{array}$ & heuteurs \\
\hline Iwaizum & 7 & 0 & 7 & 1 & 4 & 200 & 80 & 500 & Hameau cotier & 0 & $\begin{array}{l}\text { Collines a a Pinterieur des } \\
\text { terres }\end{array}$ & $\begin{array}{l}\text { Reliefs } \\
\text { intírieur }\end{array}$ \\
\hline Myako & 420 & 94 & 514 & 10 & 18 & 4005 & 2470 & 11000 & $\begin{array}{l}\text { Zore urbaine et hameau } \\
\text { cofier }\end{array}$ & $\Delta$ & Plaine cottere & plaine \\
\hline Yamada & 604 & 149 & 753 & 5 & 7 & 3167 & 3349 & 6057 & $\begin{array}{l}\text { Zore uroaine et hameau } \\
\text { côfier }\end{array}$ & $\circ$ & Plaine côtèrrs & plaine \\
\hline Otsuchi & 803 & 455 & 1258 & 4 & 5 & 3717 & 4103 & 7322 & $\begin{array}{l}\text { Zore urbaine et hameau } \\
\text { cofier }\end{array}$ & * & Flaine côtêre & plaine \\
\hline Kameishi & 888 & 152 & 1040 & 7 & 10 & 3655 & 3730 & 7453 & $\begin{array}{l}\text { Zore urbaine et hamoau } \\
\text { cofier }\end{array}$ & o & Pente côtère & 䋖面地 \\
\hline Otunato & 340 & 80 & 420 & 8 & 11 & 3934 & 4472 & 8437 & $\begin{array}{l}\text { Zore urbaine et hameau } \\
\text { côfier }\end{array}$ & $\circ$ & $\begin{array}{l}\text { Penle cốtère el+ Plaine } \\
\text { â lintárieur des lerres }\end{array}$ & heuteurs \\
\hline Rikuzentaakata & 1556 & 217 & 1773 & 13 & 7 & 3241 & 7701 & 8695 & $\begin{array}{l}\text { Zore urbaine et hameau } \\
\text { coffer }\end{array}$ & * & Flaine oôtêre & plaine \\
\hline
\end{tabular}

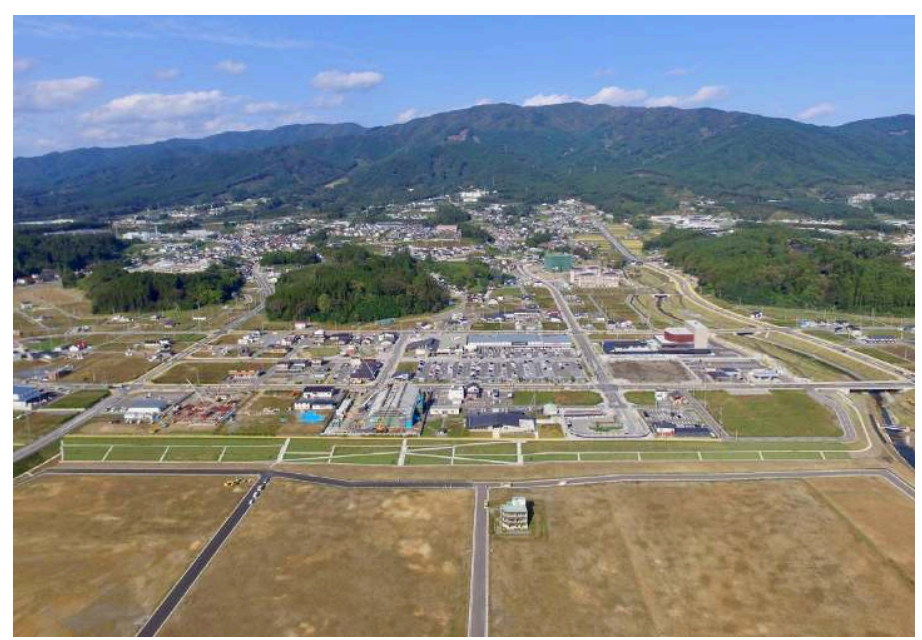

Fig. 05

Zone urbaine centrale de la ville de Rikuzentakata après la reconstruction des infrastructures : élévation globale d'environ $10 \mathrm{~m}$ du sol. Il y a une bibliothèque et des installations commerciales dans le centre. Le bâtiment en construction (vert) à l'arrière droit est le nouvel hôtel de ville. 
En outre, lors de l'examen du plan de reconstruction, la paralysie des fonctions administratives due à la destruction des bâtiments publics, ainsi qu'à la topographie basse des zones urbaines détruites le 11 mars, a joué un rôle important. Dans des sites tels que Rikuzentakata ou Ōtsuchi, lorsque tout le centre-ville a été inondé et détruit, les bâtiments publics (mairies, centres de gestion des crises, antennes gouvernementales locales, etc.) ont été relocalisés en hauteur, au sein d'espaces définis comme étant des zones de refuge et de secours en cas de tsunami. Dans des villes comme Yamada et Ōfunato, où le centre-ville a été endommagé mais pas les bâtiments publics, ces derniers n'ont pas été déplacés et ces endroits, restés intacts, ont été désignés comme zones de secours et de refuge. Les hôpitaux et casernes de pompiers, essentiels en cas de catastrophe, sont construits en dehors des zones inondables dans toutes les municipalités, et des routes sont percées pour permettre un accès même en cas d'inondation. La route nationale 45 et les lignes de chemins de fer, les axes les plus importants de la zone côtière, ont globalement été reconstruits sur leur site d'origine, avec des modifications et surélévations mineures - sauf dans le département de Miyagi pour le chemin de fer. En tant que ligne de la compagnie semi-publique JR-Est, celui-ci devait être restauré sur site par la JR (Japan Railways), mais comme certaines communes ont vu leur centre déplacé en hauteur, la ligne JR a suivi et son tracé a été modifié pour suivre la relocalisation des zones urbaines. L'ancien tracé de la voie ferrée qui reliait les villes d'Ōfunato et Kesennuma a été goudronné et aménagé en " Bus Rapid Transit », une ligne de bus en site propre. 
114 | Mirake Satoshi | Les enjeux de l'urbanisme post-catastrophe...

\section{TABLEAU 03}

Projets de reconstruction et schémas de relocalisation dans chaque commune.

\begin{tabular}{|c|c|c|c|c|c|}
\hline \multirow[b]{2}{*}{ Commune } & \multicolumn{4}{|c|}{ Type de relogement } & \multirow[b]{2}{*}{$\begin{array}{l}\text { Type de mesure } \\
\text { de relogement }\end{array}$} \\
\hline & $\begin{array}{c}\text { A } \\
\text { Relocalisation } \\
\text { collective des } \\
\text { logements } \\
\text { b sh }\end{array}$ & $\begin{array}{c}\text { B } \\
\text { Renforcement des } \\
\text { mesures de prévention } \\
\text { dans les hameaux liés à } \\
\text { l'industrie de la pêche } \\
\text { gyosh }\end{array}$ & $\begin{array}{c}\text { C } \\
\text { Remembrem } \\
\text { ent urbain }\end{array}$ & $\begin{array}{c}\text { D } \\
\text { Logements } \\
\text { collectifs publics } \\
\text { pour les sinistrés } \\
\text { saik }\end{array}$ & \\
\hline Hirono & & $\circ$ & & $\circ$ & $B+D$ \\
\hline Kuji & & $\circ$ & & $\circ$ & $B+D$ \\
\hline \multirow{4}{*}{ Noda } & \multirow{4}{*}{$\circ$} & \multirow{4}{*}{$\circ$} & \multirow{4}{*}{$\circ$} & \multirow{4}{*}{$\circ$} & $A+D$ \\
\hline & & & & & $A+C+D$ \\
\hline & & & & & $B+D$ \\
\hline & & & & & B \\
\hline Fudai & & $\circ$ & & & B \\
\hline Tanohata & & $\circ$ & & $\circ$ & $B+D$ \\
\hline Iwaizumi & & $\circ$ & & $\circ$ & $B+D$ \\
\hline \multirow{6}{*}{ Miyako } & \multirow{6}{*}{$\circ$} & \multirow{6}{*}{$\circ$} & \multirow{6}{*}{$\circ$} & \multirow{6}{*}{$\circ$} & A \\
\hline & & & & & $A+D$ \\
\hline & & & & & $A+C$ \\
\hline & & & & & $A+C+D$ \\
\hline & & & & & B \\
\hline & & & & & D \\
\hline \multirow{4}{*}{ Yamada } & \multirow{4}{*}{$\circ$} & & \multirow{4}{*}{$\circ$} & & A \\
\hline & & & & & $A+C$ \\
\hline & & & & & B \\
\hline & & & & & $B+C$ \\
\hline & & & & \multirow{5}{*}{$\circ$} & A \\
\hline & & & & & $A+D$ \\
\hline Ōtsuchi & $\circ$ & & $\circ$ & & $A+C$ \\
\hline & & & & & $A+C+D$ \\
\hline & & & & & $\mathrm{D}$ \\
\hline \multirow{4}{*}{ Kamaishi } & \multirow{4}{*}{$\circ$} & \multirow{4}{*}{$\circ$} & \multirow{4}{*}{$\circ$} & & A \\
\hline & & & & & $A+C$ \\
\hline & & & & & B \\
\hline & & & & & $C$ \\
\hline \multirow{4}{*}{ Ōfunato } & \multirow{4}{*}{$\circ$} & & \multirow{4}{*}{$\circ$} & \multirow{4}{*}{$\circ$} & A \\
\hline & & & & & $A+D$ \\
\hline & & & & & D \\
\hline & & & & & C \\
\hline \multirow{2}{*}{ Rikuzentakata } & \multirow{2}{*}{$\circ$} & & \multirow{2}{*}{$\circ$} & & A \\
\hline & & & & & $C$ \\
\hline
\end{tabular}


Le tableau 03 présente les projets envisagés dans les 12 villes et villages des zones touchées par le tsunami, le long de la côte du département d'Iwate. Dans la partie sud, de nombreux districts ont mis en œuvre des plans de relocalisation groupée des habitations ${ }^{5}$, alors que dans la partie nord de la zone, de tels regroupements en hauteur sont moins courants. Dans ces communes du Nord, on a privilégié le renforcement des pratiques de prévention des catastrophes au sein des communautés ${ }^{6}$, qui sont essentiellement composées de pêcheurs. Dans des bourgs de pêche, où l'essentiel de l'activité se fait avec la mer, on n'a pas délimité de zones à risque interdite aux habitations, et seules les communautés ou familles qui le souhaitent peuvent demander à être déplacées sur des terrains plus élevés. Dans les faits, pour les zones où un consensus sur la définition du périmètre interdit à l'habitat a pu être trouvé, c'est l'ensemble des hameaux regroupés qui a été déplacé en hauteur. En revanche, et essentiellement s'agissant des villages de pêcheurs, où des consensus n'ont pas pu être trouvés au sein des communautés pour délimiter une zone non habitable, c'est la prévention qui a été choisie et on a dû laisser le choix aux habitants de se déplacer, ou non, vers les hauteurs.

Dans le Nord du Sanriku, le choix du renforcement de la prévention communautaire des hameaux de pêcheurs a été privilégié, comme, par exemple, pour le village de Tanohata. Les propriétaires fonciers n'ont pas accepté le périmètre de la zone à risque, ni le déplacement de leurs habitations. De même dans la ville d'Imaizumi, où de nombreux ménages voulaient continuer à vivre sur leur terrain d'origine, considérant que leurs habitations étaient sûres malgré les inondations. Idem pour la commune de Kuji, où plus de cinq familles ont refusé de déménager. Inversement, dans la partie sud de la côte du Sanriku, le principe de base a été d'appliquer la relocalisation de l'habitat regroupé en hauteur, et ce n'est que lorsque c'était impossible que l'on a dû opter in fine pour la prévention communautaire,

5. Il s'agit des opérations de bōsai shüdan iten sokushin 防災集団移転促進, mot à mot "promotion de la relocalisation collective à des fins de prévention des catastrophes". Abrégé en boshū 防集, ce sont des plans de relogement de l'ensemble des habitations d'un quartier détruit vers un nouveau site en hauteur, à l'abri des tsunamis. (N.D.T.) 6. On parle alors d'opération de gyogyō shüraku bōsai kinō kyōka 漁業集落防災機能強化 (abrégé en gyoshū 業集), soit le renforcement des outils et mesures de prévention des catastrophes au sein des hameaux liés à l'industrie de la pêche. 
auprès des habitants de la zone à risque. Il y a également les exemples particuliers d'Osawa et d'Ōura dans la ville de Yamada. Si les digues de la baie de Yamada ont été reconstruites au niveau L1, les résultats de la simulation de tsunami montrent que ces deux districts ne seraient pas inondés, même en cas de tsunami de niveau 2. Par conséquent, il est difficile d'y tracer une zone à risque de catastrophe et d'inciter les habitants à se déplacer. Aussi c'est le renforcement de la prévention qui a été choisie. Généralement, dans de nombreux sites, les deux principes ont été combinés, protection avec relocalisation en hauteur et politique accrue de prévention communautaire.

Bien que la relocalisation des villes sur des terrains plus élevés soit la meilleure méthode de prévention des catastrophes face aux tsunamis, l'utilisation des terres en zone inondable se pose tout de même pour les terrains autres que ceux résidentiels. Pour ceux-ci, des remembrements urbains ont été mis en œuvre. Cela tient au fait que les transferts de propriété de terrain depuis la zone inondable vers les nouvelles zones d'habitat groupées en hauteur, ne sont valables que pour les terrains résidentiels. Les terrains industriels ne sont pas éligibles à ce type d'échange et de relocalisation. En outre, en raison de l'importance de l'industrie de la pêche, les centresvilles de ces communes s'étaient développés sur les zones basses, le long de la route nationale 45, principale voie de transport de la région. Cette fois encore, les dégâts ont été les plus sévères dans ces zones basses de centreville, notamment à Rikuzentakata, Ōfunato, Kamaishi, Ōtsuchi, Yamada et Tarō à Miyako. Ces zones étant également les centres du commerce de la région, leur perte entraîne mécaniquement un déclin économique. Pour éviter que cela ne se produise, il est nécessaire de revitaliser ces centresvilles. Les projets de redéveloppement des infrastructures intègrent ainsi un remembrement urbain concernant ces zones commerciales et industrielles afin de les inclure dans la reconstruction post-catastrophe. Aussi les villes de Rikuzentakata, Kamaishi, Ōfunato et Yamada ont adopté très rapidement les projets de reconstruction post-tsunami, afin de reconstruire le plus rapidement possible leurs quartiers commercial et industriel.

Même avant la catastrophe, le Japon était confronté aux problèmes du vieillissement des populations. Le grand désastre du Japon de l'Est a fait de ces problèmes une réalité bien présente. Il est difficile pour les retraités âgés, dont les maisons ont été complétement ou partiellement détruites, de reconstruire leurs habitations, pour des raisons financières. C'est pourquoi 
un certain nombre de projets de logements publics ${ }^{7}$ ont été planifiés et construits pour les ménages les plus âgés, en difficulté financière.

\section{Les modalités d'évolution des plans et projets de reconstruction}

Dans cette partie, nous clarifions les changements dans les plans de reconstruction à long terme et leurs facteurs. Nous analysons les données concernant les plans de relocalisation groupée de l'habitat en hauteur et des plans de renforcement de la prévention dans les bourgs de pêche de la commune de Kamaishi, en comparant les données concernant la réalité de l'occupation des zones résidentielles avec ce qui était initialement prévu, ainsi que les résultats d'une enquête d'opinion auprès des habitants de ces zones.

\section{1. Évolution des plans de reconstruction des zone résidentielles}

Le tableau 04 montre l'évolution de la planification des terrains résidentiels par district. Le rapport entre le plan effectivement réalisé et le plan initial nous permet de calculer un taux de modification; il concerne les surfaces planifiées ou le nombre de maisons finalement construites.

7. Les saigai köei jütaku 災害公営住宅, abrégés en saikō 災公, des logements collectifs publics généralement en barre de 5 à 10 étages. (N.D.T.) 
TABLEAU 04

Changements dans la planification pour chaque district.

\begin{tabular}{|c|c|c|c|c|c|c|c|}
\hline District & $\begin{array}{c}\text { Détail de } \\
\text { l'opération }\end{array}$ & $\begin{array}{l}\text { Plan } \\
\text { initial } \\
\text { (A) }\end{array}$ & $\begin{array}{l}\text { Plan à } \\
\text { la mise } \\
\text { en } \\
\text { œuvre } \\
\text { (B) }\end{array}$ & $\begin{array}{l}\text { Plan } \\
\text { effecti- } \\
\text { vement } \\
\text { réalisé } \\
\text { (C) }\end{array}$ & $\begin{array}{l}\text { Nombre } \\
\text { de mai- } \\
\text { sons } \\
\text { vacantes }\end{array}$ & $\begin{array}{c}\text { Taux-1 } \\
\text { (C/A) }\end{array}$ & $\begin{array}{l}\text { Taux-2 } \\
(\mathrm{C} / \mathrm{B})\end{array}$ \\
\hline \multirow[t]{3}{*}{ A-1 } & Surface aménagée & 32448 & 14458 & 18330 & - & 0,56 & 1,27 \\
\hline & $\begin{array}{c}\text { Maisons en recons- } \\
\text { truction sur fonds } \\
\text { propres }\end{array}$ & 69 & 18 & 18 & 6 & 0,26 & 1 \\
\hline & $\begin{array}{l}\text { Logements publics } \\
\text { réservés aux } \\
\text { sinistrés }\end{array}$ & 10 & 9 & 7 & - & - & - \\
\hline \multirow[t]{3}{*}{ A-2 } & Surface aménagée & 29198 & 25283 & 27218 & - & 0,93 & 1,08 \\
\hline & $\begin{array}{c}\text { Maisons en recons- } \\
\text { truction sur fonds } \\
\text { propres }\end{array}$ & 48 & 31 & 31 & 2 & 0,65 & 1 \\
\hline & $\begin{array}{l}\text { Logements publics } \\
\text { réservés aux } \\
\text { sinistrés }\end{array}$ & - & 13 & 10 & - & - & - \\
\hline \multirow[t]{3}{*}{ A-3 } & Surface aménagée & 53107 & 49094 & 39272 & - & 0,74 & 0,80 \\
\hline & \begin{tabular}{|c}
$\begin{array}{c}\text { Maisons en recons- } \\
\text { truction sur fonds } \\
\text { propres }\end{array}$ \\
\end{tabular} & 105 & 36 & 32 & 1 & 0,30 & 0,89 \\
\hline & $\begin{array}{l}\text { Logements publics } \\
\text { réservés aux } \\
\text { sinistrés }\end{array}$ & - & 30 & 31 & - & - & - \\
\hline \multirow[t]{3}{*}{ A-4 } & Surface aménagée & 19320 & 9728 & 8543 & - & 0,44 & 0,88 \\
\hline & $\begin{array}{c}\text { Maisons en recons- } \\
\text { truction sur fonds } \\
\text { propres }\end{array}$ & 30 & 9 & 10 & - & 0,33 & 1,11 \\
\hline & $\begin{array}{c}\text { Logements publics } \\
\text { réservés aux } \\
\text { sinistrés } \\
\end{array}$ & - & 9 & 9 & - & - & - \\
\hline \multirow[t]{3}{*}{ A-5 } & Surface aménagée & - & - & 1920 & - & - & - \\
\hline & \begin{tabular}{|c}
$\begin{array}{c}\text { Maisons en recons- } \\
\text { truction sur fonds } \\
\text { propres }\end{array}$ \\
\end{tabular} & 4 & 2 & 2 & - & 0,50 & 1 \\
\hline & $\begin{array}{l}\text { Logements publics } \\
\text { réservés aux } \\
\text { sinistrés }\end{array}$ & - & - & - & - & - & - \\
\hline
\end{tabular}




\begin{tabular}{|c|c|c|c|c|c|c|c|}
\hline District & $\begin{array}{l}\text { Détail de } \\
\text { l'opération }\end{array}$ & $\begin{array}{l}\text { Plan } \\
\text { initial } \\
\text { (A) }\end{array}$ & $\begin{array}{c}\text { Plan à } \\
\text { la mise } \\
\text { en } \\
\text { œuvre } \\
\text { (B) }\end{array}$ & $\begin{array}{l}\text { Plan } \\
\text { effecti- } \\
\text { vement } \\
\text { réalisé } \\
\text { (C) }\end{array}$ & $\begin{array}{l}\text { Nombre } \\
\text { de mai- } \\
\text { sons } \\
\text { vacantes }\end{array}$ & $\begin{array}{l}\text { Taux-1 } \\
\text { (C/A) }\end{array}$ & $\begin{array}{l}\text { Taux-2 } \\
(\mathrm{C} / \mathrm{B})\end{array}$ \\
\hline \multirow[t]{3}{*}{ A-6 } & Surface aménagée & 9360 & 27023 & 28514 & - & 3,05 & 1,06 \\
\hline & $\begin{array}{c}\text { Maisons en recons- } \\
\text { truction sur fonds } \\
\text { propres }\end{array}$ & 19 & 11 & 10 & - & 0,53 & 0,91 \\
\hline & $\begin{array}{l}\text { Logements publics } \\
\text { réservés aux } \\
\text { sinistrés } \\
\end{array}$ & 10 & 12 & 8 & - & - & - \\
\hline \multirow[t]{3}{*}{ A-7 } & Surface aménagée & 33770 & 55951 & 64993 & - & 1,92 & 1,16 \\
\hline & $\begin{array}{c}\text { Maisons en recons- } \\
\text { truction sur fonds } \\
\text { propres }\end{array}$ & 33 & 60 & 66 & - & 2 & 1,10 \\
\hline & $\begin{array}{l}\text { Logements publics } \\
\text { réservés aux } \\
\text { sinistrés } \\
\end{array}$ & 23 & 29 & 25 & - & - & - \\
\hline \multirow[t]{3}{*}{ A-8 } & Surface aménagée & 4770 & 5389 & 3819 & - & 0,80 & 0,71 \\
\hline & $\begin{array}{c}\text { Maisons en recons- } \\
\text { truction sur fonds } \\
\text { propres }\end{array}$ & 12 & 5 & 5 & 1 & 0,42 & 1 \\
\hline & $\begin{array}{l}\text { Logements publics } \\
\text { réservés aux } \\
\text { sinistrés } \\
\end{array}$ & - & 5 & 5 & - & - & - \\
\hline \multirow[t]{3}{*}{ A-9 } & Surface aménagée & - & - & 9821 & - & - & - \\
\hline & $\begin{array}{c}\text { Maisons en recons- } \\
\text { truction sur fonds } \\
\text { propres }\end{array}$ & 8 & 5 & 5 & - & 0,63 & 1 \\
\hline & $\begin{array}{l}\text { Logements publics } \\
\text { réservés aux } \\
\text { sinistrés } \\
\end{array}$ & 3 & - & - & - & - & - \\
\hline \multirow[t]{3}{*}{ A-10 } & Surface aménagée & 2400 & 2400 & 2400 & - & 1 & 1 \\
\hline & $\begin{array}{c}\text { Maisons en recons- } \\
\text { truction sur fonds } \\
\text { propres }\end{array}$ & 4 & 4 & 4 & - & 1 & 1 \\
\hline & $\begin{array}{l}\text { Logements publics } \\
\text { réservés aux } \\
\text { sinistrés }\end{array}$ & 9 & 9 & 13 & $\begin{array}{l}\text { Loge- } \\
\text { ments } \\
\text { collectifs } \\
\text { vacants }\end{array}$ & - & - \\
\hline
\end{tabular}


Mirake Satoshi ～Les enjeux de l'urbanisme post-catastrophe...

\begin{tabular}{|c|c|c|c|c|c|c|c|}
\hline District & $\begin{array}{l}\text { Détail de } \\
\text { l'opération }\end{array}$ & $\begin{array}{l}\text { Plan } \\
\text { initial } \\
\text { (A) }\end{array}$ & $\begin{array}{c}\text { Plan à } \\
\text { la mise } \\
\text { en } \\
\text { œuvre } \\
\text { (B) }\end{array}$ & $\begin{array}{l}\text { Plan } \\
\text { effecti- } \\
\text { vement } \\
\text { réalisé } \\
\text { (C) }\end{array}$ & $\begin{array}{l}\text { Nombre } \\
\text { de mai- } \\
\text { sons } \\
\text { vacantes }\end{array}$ & $\begin{array}{l}\text { Taux-1 } \\
\text { (C/A) }\end{array}$ & $\begin{array}{l}\text { Taux-2 } \\
(\mathrm{C} / \mathrm{B})\end{array}$ \\
\hline \multirow[t]{3}{*}{ A-11 } & Surface aménagée & 14640 & 11462 & 12098 & - & 0,38 & 1,06 \\
\hline & \begin{tabular}{|c|}
$\begin{array}{c}\text { Maisons en recons- } \\
\text { truction sur fonds } \\
\text { propres }\end{array}$ \\
\end{tabular} & 17 & 12 & 12 & 1 & 0,71 & 1 \\
\hline & $\begin{array}{c}\text { Logements publics } \\
\text { réservés aux } \\
\text { sinistrés } \\
\end{array}$ & 16 & 12 & 12 & - & - & - \\
\hline \multirow[t]{3}{*}{ A-12 } & Surface aménagée & 9370 & - & - & - & - & - \\
\hline & $\begin{array}{c}\text { Maisons en recons- } \\
\text { truction sur fonds } \\
\text { propres }\end{array}$ & 23 & - & - & - & - & - \\
\hline & & - & - & - & - & - & - \\
\hline \multirow[t]{3}{*}{ A-13 } & Surface aménagée & 22610 & 29193 & 20920 & - & 0,93 & 0,72 \\
\hline & $\begin{array}{c}\text { Maisons en recons- } \\
\text { truction sur fonds } \\
\text { propres }\end{array}$ & 37 & 25 & 18 & 1 & 0,49 & 0,72 \\
\hline & $\begin{array}{l}\text { Logements publics } \\
\text { réservés aux } \\
\text { sinistrés } \\
\end{array}$ & 59 & - & - & - & - & - \\
\hline \multirow[t]{3}{*}{ A-14 } & Surface aménagée & 10510 & 4533 & 3400 & - & 0,32 & 0,75 \\
\hline & $\begin{array}{c}\text { Maisons en recons- } \\
\text { truction sur fonds } \\
\text { propres }\end{array}$ & 19 & 2 & 1 & - & 0,05 & 0,50 \\
\hline & $\begin{array}{l}\text { Logements publics } \\
\text { réservés aux } \\
\text { sinistrés } \\
\end{array}$ & - & 8 & 8 & - & - & - \\
\hline
\end{tabular}

Si l'on considère l'évolution du ratio de modification pour les surfaces bâties, celui-ci est supérieur à 1 dans seulement trois districts. Les ratio des huit autres districts sont tous inférieurs à 1 , ce qui indique une réduction de la taille de la zone aménagée par rapport à ce qui était planifié. C'est tout particulièrement le cas des zones A-1, A-4 et A-14. Il existe par ailleurs des zones où le plan a été tout simplement annulé, parce qu'il n'y avait plus de candidats pour occuper les logements.

Le fait que la superficie globale n'ait pas beaucoup changé alors que la superficie de nombreux districts a diminué est dû à l'effet de l'intégration 
des zones A-5 et A-9 après l'élaboration du plan d'aménagement. En outre, si l'on examine le ratio du nombre de maisons reconstruites individuellement ${ }^{8}$, de nombreux districts ont un taux de 0,7 ou moins, et certains districts ont même un ratio inférieur à 0,5 . En d'autres termes, le nombre de personnes souhaitant reconstruire leur maison par leurs propres moyens a eu plutôt tendance à diminuer par rapport à ce qui avait été planifié. En examinant le ratio réel, nous observons qu'il a diminué à 0,7 dans certains districts, mais il n'est pas faible au point que l'on puisse dire que de nombreux résidents ont changé leurs intentions entre le plan final et le plan effectivement réalisé sur le terrain. Les enquêtes d'opinions individuelles auprès des habitants concernés par le relogement permettent de comprendre les raisons de l'annulation des demandes, à l'origine du plus faible nombre de maisons construites par rapport à ce qui était prévu.

8. Dénommé jiriki saikento 自力再建戸, dans ce cas, un foyer se voit octroyer une parcelle sur laquelle il fait bâtir sa maison sur ses fonds propres. Une partie est cependant financée par les aides à la reconstruction, complétée par les économies du ménage qui peut ainsi choisir librement la taille de la maison, son plan et la qualité du bâti. 


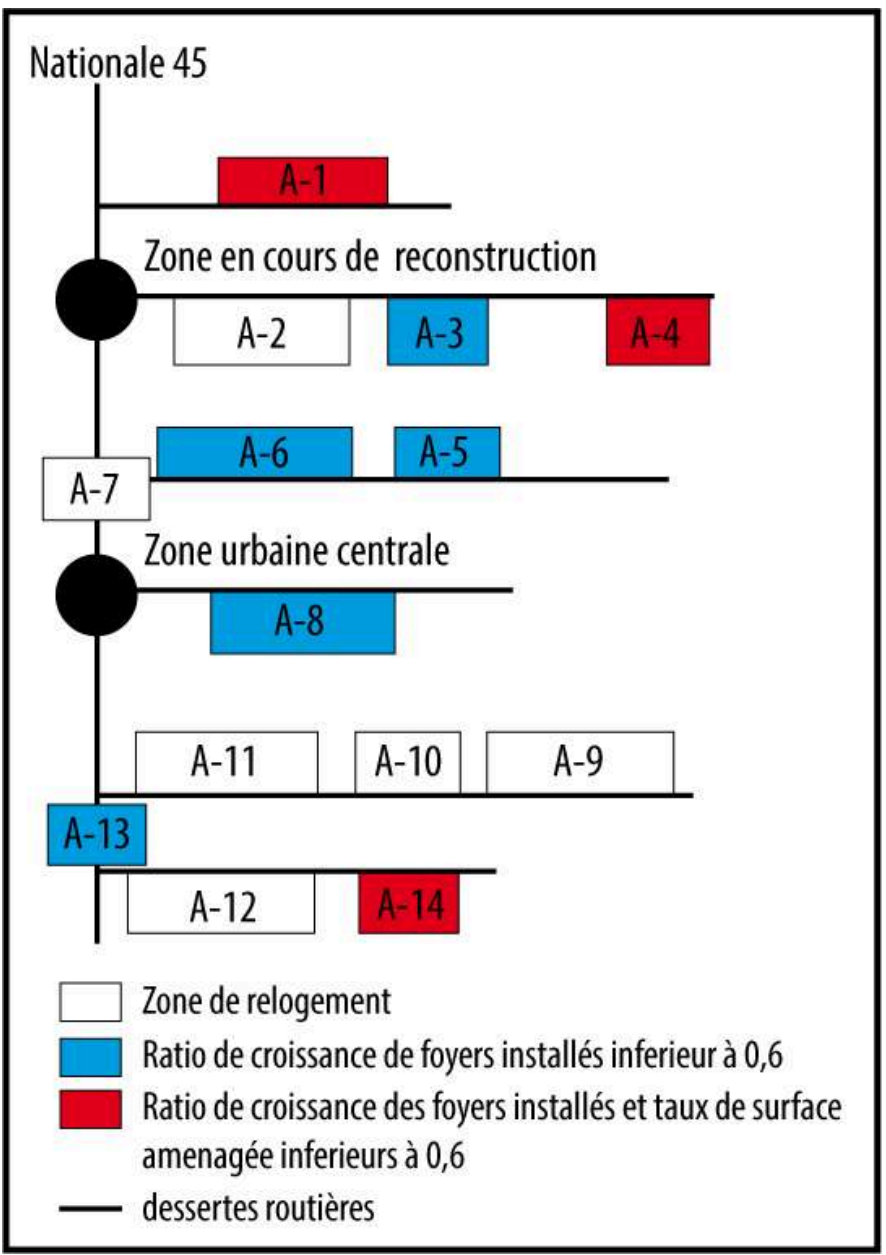

Fig. 06

Schéma de l'emplacement de chaque district.

La localisation des parcelles proposées pour le relogement joue également un rôle dans l'évolution des plans de relogement (fig. 06). On constate que les districts où le taux de variation est le plus faible, sont généralement situés au long des péninsules. Par ailleurs, le taux de variation du nombre de maisons reconstruites individuellement dans les quartiers situés 
au nord du centre-ville est légèrement plus faible que pour les quartiers du sud du centre-ville, ce qui indique que le nombre de maisons reconstruites individuellement au nord est en baisse. Dans ces zones, les plans initiaux tablaient par endroit sur la construction de 50 à 100 unités, voire plus. Un grand nombre de parcelles était donc prévu au départ. Le taux d'évolution étant à la baisse, cela indique que plusieurs personnes ont changé leurs intentions au cours du processus. On constate même que plus le nombre de parcelles prévues pour ces constructions était élevé, plus la différence à la baisse du nombre de constructions effectivement achevées est importante. La raison du doublement du nombre de maisons reconstruites individuellement, par rapport au plan de départ, pour la zone A-7, s'explique par le fait que ces terrains sont situés le long de la route nationale. Cela accroît l'attractivité de la zone et les demandes. Il y a aussi le fait que jusqu'à ce que le prix de l'opération et le nombre de parcelles à aménager soient décidés, on a invité des habitants d'autres zones à risque à venir s'installer précisément dans la zone A-7.

En revanche, le nombre d'unités en reconstruction sur fonds propres dans les districts du sud est plutôt faible. Selon un responsable de la mairie de Kamaishi, la raison en est que " la fabrication du consensus était plus rapide parce qu'il y avait beaucoup de petits quartiers (des zones avec moins de ménages) » et que cela "a permis de réduire les délais entre l'élaboration du plan et sa mise en œuvre effective ", d'où un décalage plus faible entre le départ et l'arrivée.

On constate donc que le taux de variation tend à être à la baisse dans les zones comportant un grand nombre d'unités résidentielles et que, dans ce cas, c'est la diminution de leur nombre par rapport à celui du nombre de parcelles prévues par les plans de départ qui produit de la vacance.

\section{2. Les facteurs de l'évolution des plans de relogement}

L'évolution vers des plans de relogement plus modestes, ainsi que l'apparition de parcelles vacantes au sein de ces opérations (tableau 05), s'expliquent essentiellement par les rétractions de candidature au relogement et par le vieillissement des populations dont une partie a été relogées en établissements spécialisés après la catastrophe. Huit ans après le séisme du 11 mars, on constatait déjà que de nombreux ménages âgés avaient emménagé chez leurs enfants en raison de problèmes de santé dus à la vieillesse, 
ou avaient renoncé à reconstruire leur maison parce qu'ils avaient quitté leur emploi. Ces problèmes concernant les personnes âgées avaient été signalés dès l'élaboration des plans de reconstruction. Mais, bien que des ajustements aient été effectués sur la base des résultats de la première série de demandes de relogement, ce sont les annulations au moment de la dernière étape du processus d'attribution des parcelles qui sont à l'origine des taux de vacances actuels.

\section{TABLEAU 05}

Enquête municipale concernant les parcelles vacantes.

\begin{tabular}{|l|l|}
\hline Caractéristiques principales & Ville de Kamaishi \\
\hline Type de surface de parcelles & lots de $330 \mathrm{~m}^{2}, 264 \mathrm{~m}^{2}$ et $198 \mathrm{~m}^{2}$ \\
\hline Type de logements publics & lots de $330 \mathrm{~m}^{2}, 264 \mathrm{~m}^{2}$ et $198 \mathrm{~m}^{2}$ \\
\hline Type de relocalisation & $\begin{array}{l}\text { Le classement en gyoshü appliqué par défaut pour les } \\
\text { personnes habitants hors de la zone de böshü }\end{array}$ \\
\hline $\begin{array}{l}\text { Principale cause d'apparition } \\
\text { de parcelles inoccupées }\end{array}$ & $\begin{array}{l}\text { âge élevé des foyers (moyenne de } 62 \text { ans dans la zone } \\
\text { A-1) }\end{array}$ \\
& $\begin{array}{l}\text { ressources financières limitées chez les personnes } \\
\text { âgées }\end{array}$ \\
& $\begin{array}{l}\text { déménagement à proximité des enfants habitant hors } \\
\text { de la ville }\end{array}$ \\
& $\begin{array}{l}\text { impossibilité de finalement réunir les fonds néces- } \\
\text { saires à la reconstruction }\end{array}$ \\
& $\begin{array}{l}\text { l'aménagement de la zone de relogement ne corres- } \\
\text { pond pas aux attentes initiales }\end{array}$ \\
\hline Autres & $\begin{array}{l}\text { rôle des associations de machizukuri } \\
\text { - la petite taille des zones d'aménagement facilite } \\
\text { l'achèvement rapide des travaux }\end{array}$ \\
\hline
\end{tabular}

De nombreuses raisons peuvent expliquer les grands nombres de rétractation dans la demande d'une parcelle à construire dans les zones de relogement. Tout d'abord, il n'y a aucun moyen de recours des aménageurs

9. Nous conservons le terme japonais de machizukuri まちづくり, une forme d'urbanisme collaboratif qui permet aux habitants d'un quartier de participer activement à l'élaboration des plans d'aménagement, en l'occurrence ceux pour la reconstruction post-catastrophe. (N.D.T.) 
vis-à-vis des ménages qui ont fait la première démarche de demande de parcelle, mais qui annulent à la fin du processus. C'est souvent le cas pour raisons de problèmes familiaux ou de santé, mais aussi parce que les candidats au relogement veulent parfois disposer de plus d'options dans le choix de leur parcelle et ces reconfigurations produisent des angles non bâtis au sein des périmètres. Il faudrait pouvoir limiter les possibilités de transformer les parcelles lors de la mise en œuvre du projet, afin de réduire le nombre de parcelles vacantes. Mais cela est aujourd'hui impossible et, finalement, tout dépend des négociations avec les personnes concernées, pour les convaincre de maintenir leur demande avec le minimum de réajustement des parcelles.

La ville de Kamaishi a jugé que le conseil de machizukuri de la ville fonctionnait plutôt bien pour éviter ce type de problème. Le fait que le projet de reconstruction ait été réalisé sur la base des intentions des résidents exprimées au sein du conseil de machizukuri, n'a entraîné que de légères modifications dans le nombre final de parcelles à construire lors de la mise en œuvre du plan. De plus, des petits districts ont pu commencer leurs projets plus tôt, ce qui a réduit les disparités avec les plans initiaux. D'autre part, dans la plupart des quartiers de la ville de Kamaishi, les terrains d'origine ont été surélevés, pour créer des complexes résidentiels destinés au relogement des évacués. Mais les victimes qui habitaient en dehors de la zone à risque avant la catastrophe ne sont pas éligibles pour le relogement hors de leur quartier d'origine et ne peuvent pas demander une parcelle de terrain dans les zones de relogement. Cela limite les options et aide à conserver des plans d'aménagement qui n'évoluent pas trop au cours du temps. On limite ainsi le risque d'avoir des parcelles aménagées mais inoccupées.

\section{3. Les réponses à la transformation des plans d'aménagement}

Dans de nombreux districts de relogement, les plans ont été modifiés de manière significative par rapport au projet initial. Cette adaptation est le résultat des consultations effectuées, longuement, auprès de chaque ménage à reloger, ce qui montre l'importance de telles enquêtes individuelles. Ensuite, dans le cas de la ville de Kamaishi, trois modèles type (en taille et en forme) de parcelles ont été proposés aux habitants. Les plans de relogement doivent les suivre, en élaborant des combinaisons, en fonction des sites choisis. Dans les hameaux situés en pente raide, la superficie du terrain à aménager tend à être plus importante, et une réduction des quantités de 
terre et de sable à excaver du relief entraîne une réduction des coûts. Les révisions détaillées du plan, tout au long du processus, ont permis d'ajuster la taille de la surface à aménager au plus près des besoins réels et d'économiser sur les traveaux. En établissant trois modèles de taille et de forme de parcelles, il est possible non seulement de répondre aux besoins des résidents, mais aussi d'affiner le périmètre de la zone de relogement. En outre, certaines zones ont été surélevées pour créer des aires d'habitat regroupé à disposition des seules personnes originaires des zones à risque d'inondation. Cela permet de limiter le nombre de parcelles à aménager. Cependant, comme on ne peut pas faire venir dans ces zones d'autres personnes que celles qui avaient le droit de postuler pour l'obtention d'une parcelle, les rétractations ont mécaniquement produit de la vacance foncière. Cela explique que, par la suite, on a commencé à accepter des candidatures de personnes venant d'autres quartiers que ceux touchés par la catastrophe pour réduire le nombre de parcelles vacantes.

\section{L'impact de la reconstruction à long terme}

\section{1. Impacts et changements dans l'industrie locale}

Les principales industries de la zone côtière du Sanriku sont la pêche et la transformation des produits de la mer. Bien que la plupart des infrastructures portuaires aient été détruites par le tsunami, l'Agence nationale pour la pêche a rapidement remis en état les ports. Six mois après le séisme, on a pu reprendre l'ensemencement des algues wakame et des coquilles Saint-Jacques. Cela a permis de reprendre la pêche dès 2012 et de reprendre les expéditions. L’Association de promotion de la pêche de Tōkyō $(2018,2019)$ a enquêté sur le rétablissement des villages de pêcheurs dans les départements d'Iwate et de Miyagi. Elle a constaté que, bien que le nombre de pêcheurs et de captures ait diminué en raison du départ à la retraite des pêcheurs âgés, plus de $60 \%$ des indicateurs clés de la pêche se sont rétablis. Quant à l'impact du relogement sur les hauteurs, il apparaît que les pêcheurs ne ressentent aucune gêne pour se rendre au travail en voiture. Cependant, il y a une pénurie de main-d'œuvre pour les travaux communautaires : ce qui était le fait de l'entraide traditionnelle au sein des villages, comme l'écaillage des huîtres ou le traitement après récolte des algues wakame, n’a pas été restauré. 
La zone côtière du Sanriku possédait également une industrie touristique florissante qui tirait parti de ses ressources marines. Dans le village de Tanohata, des excursions en bateau étaient organisées avant le séisme et, dans la ville de Yamada, il y avait une plage sur l'île d'Oshima au milieu de la baie. Dans la ville d'Ōtsuchi, on pratiquait le surf sur la plage de Namiita. Bien que la reprise de ce type de tourisme soit moins prioritaire que le développement des infrastructures de base, un nouveau tourisme, basé sur l'échange et les récits d'expérience du tsunami s'est développé dans diverses parties du Sanriku. L'objectif est de créer de vraies relations humaines avec les visiteurs, tout en aidant à la reconstruction. Cependant, même avant le séisme, l'industrie primaire de la région était en déclin. Celle-ci va certainement péricliter dans un avenir proche, même si on tente de la relancer. Il est ainsi nécessaire de stimuler tous les potentiels de développement du Sanriku, en plus de la pêche. Dans le processus de reconstruction après le séisme, de nombreux pêcheurs ont pris conscience du déclin de la pêche. Ils cherchent aujourd'hui à développer leur industrie différemment. En outre, il existe quelques exemples de jeunes pêcheurs qui s'engagent vers un tourisme basé sur leur activité, leur permettant d'établir des relations avec les visiteurs.

La zone côtière du Sanriku a reçu le soutien du monde entier au cours de son long rétablissement après la catastrophe. Elle tente aujourd'hui de se développer non seulement avec la pêche en tant qu'industrie mais aussi sur la base d'un tourisme basé sur des relations humaines riches et mutuelles, perçues comme un des éléments de la reconstruction du capital social local.

\section{2. Dérèglement climatique et catastrophes nouvelles}

Dans le cadre de la reconstruction post-tsunami, l'accent a été mis sur les politiques de prévention des catastrophes. Cependant, les catastrophes causées par le dérèglement climatique sont devenues plus fréquentes, au Japon comme dans le reste du monde. Dans l'Archipel, des inondations et des glissements de terrain causés par de fortes pluies se produisent chaque année. Même dans les zones touchées par la catastrophe du 11 mars, on peut citer le glissement de terrain dans la ville d'Iwaizumi causé par le typhon $n^{\circ} 10$ en 2016 et celui dans la ville de Yamada, à Tanohama, causé par le typhon $n^{\circ} 19$ en 2019. 


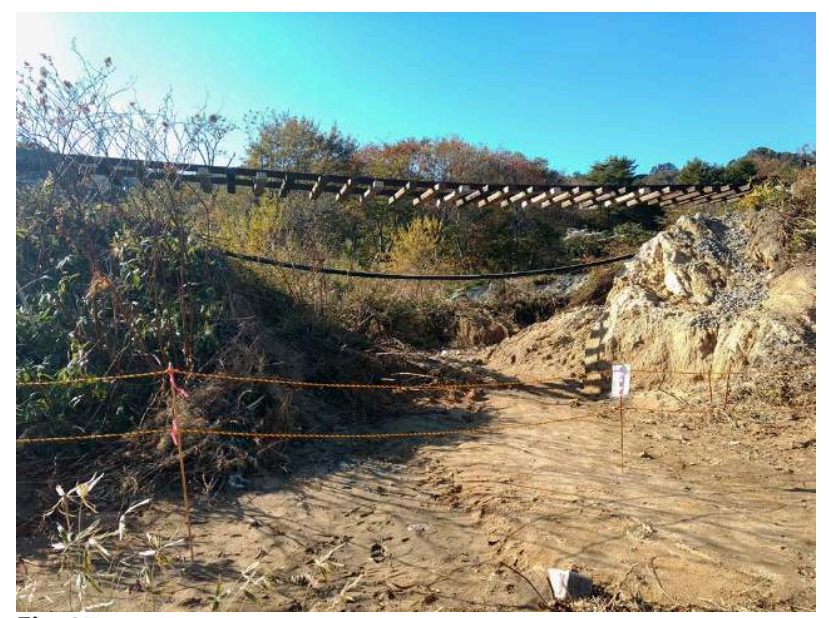

\section{Fig. 07}

Chemin de fer du Sanriku (Funakoshi, Yamada-chō) en 2019.

Les sédiments sous la ligne de chemin de fer ont été emportés par le typhon n 19.

Dans la région côtière du Sanriku, les glissements de terrain sont depuis longtemps qualifiés de "tsunamis de montagne " (yama tsunami 山津波). La région a été préparée non seulement aux tsunamis venus de la mer, mais aussi aux coulées de boue venues des hauteurs. Lors de la reconstruction post11 mars, des efforts ont aussi été déployés pour faire face aux glissements de terrain. Par exemple, le district de Nakajima, dans le bourg d'Iwaizumi, qui a été gravement endommagé par le typhon $\mathrm{n}^{\circ} 10$ en 2016, avait un temps été considéré comme un site de relocalisation potentiel de logements. Celui de la région d'Omoto a, lui, bien été aménagé, en reconvertissant des rizières proches de la gare. Un site dont certaines habitations avaient subi une inondation de leur rez-de-chaussée dans les années 1990. Lors de l'étude du plan de reconstruction, la possibilité d'une inondation par la rivière locale en cas de fortes pluies, de l'ampleur du typhon Kathleen en 1947, a ainsi été envisagée. Effectivement, le site a été inondé lors des fortes pluies de 2016.

Le quartier de Tanohama est connu pour avoir été relocalisé en hauteur à la suite du tsunami de Shōwa-Sanriku en 1933. Bien que la zone ait subi quelques dégâts dus à l'inondation et à la propagation du feu lors du séisme du 11 mars, elle a subi moins de dommages que les quartiers situés du côté de l'océan et qui ont été emportés par les eaux. Dans le cadre du projet de 
reconstruction, il a été décidé d'implanter un espace vert de prévention des catastrophes pour protéger les zones inondées et endommagées par le feu. Les fortes pluies provoquées par le typhon $\mathrm{n}^{\circ} 19$ en 2019 ont pourtant inondé le quartier de Tanohama au niveau des rez-de-chaussée et plusieurs maisons ont été détruites. En fait, les fossés de drainage ont été obstrués par la terre et le sable charriés par les fortes pluies, et les espaces verts destinés à la prévention des tsunamis ont bloqué la circulation de l'eau venue des reliefs, tel un barrage. Des fossés de drainage avaient été construits en se basant sur le fait qu'il y avait une zone de risque de glissement de terrain derrière le site et qu'il y avait un ruisseau qui collectait les eaux de pluie. Mais la quantité de pluie a dépassé les fossés, ce qui a entraîné une catastrophe inattendue. Par ailleurs, les précipitations maximales dans la ville de Yamada lors de cet épisode étaient de plus de $77 \mathrm{~mm}$ par heure et de plus de $300 \mathrm{~mm}$ en 12 heures. Il s'agit d'un record depuis le début des relevés météorologiques dans cette ville, qui équivaut à un niveau situé entre un quart et un tiers des précipitations annuelles (Japan Meteorological Agency 2019).

La prévention des catastrophes dues aux tsunamis a été considérée comme prioritaire dans le Sanriku, mais nous sommes maintenant au point où une étude complète de la prévention des catastrophes basée sur les changements climatiques est nécessaire. En particulier, le vent et la pluie deviennent plus intenses, dépassant les moyennes annuelles habituelles. Il est donc nécessaire d'envisager des contre-mesures dès que possible.

\section{Conclusion : vers une planification urbaine et régionale adaptée au déclin démographique}

Nous avons présenté l'état actuel et les défis de la reconstruction post-11 mars, en tenant compte des mérites et des démérites de la planification urbaine japonaise classique, face à des sociétés dont la population est en déclin. Les modes d'aménagement ont évolué avec cette catastrophe, tout comme les conditions économiques et démographiques locales. Le rehaussement par remblai d'une partie du bourg de Tarō a ainsi dû être abandonné, pour des raisons techniques et financières. Sur le long terme, les projets de reconstruction subissent les changements d'intention des résidents et il en résulte des problèmes de parcelles vacantes et de terrains inoccupés, après la mise en œuvre des plans de relogement. En particulier, plus il y avait d'unités de logement avant la catastrophe, 
plus la vacance est importante dans les nouveaux quartiers relocalisés en hauteur. Ce problème de vacance survient même lorsque des projets de réajustement foncier sont adoptés en substitution du déménagement entier des quartiers exposés au tsunami (fig. 08). Les principes de l'aménagement du territoire tels qu'ils ont été établis pendant la période de Haute croissance économique reposent toujours sur un principe de croissance et d'expansion urbaine continues. Les limites de ce mode de planification apparaissent très crûment lors de leur mise en œuvre dans les régions confrontées au déclin démographique et à la contraction urbaine, comme c'est le cas avec la reconstruction post-tsunami.

Dix ans après la catastrophe du 11 mars, il est peut-être temps de repenser la poursuite des projets d'aménagement sur un modèle classiques. Certains se poursuivent malgré des changements radicaux des circonstances environnantes, comme par exemple ceux induits par le dérèglement climatique. La question des digues a beaucoup à voir avec la structure foncière, mais une évolution de celle-ci (remembrement, réquisition, rachat forcé, etc.) pourrait être difficile à mettre en œuvre. Il est pourtant nécessaire de réexaminer la question des nombreuses terres inutilisées par leurs propriétaires. Par ailleurs, des catastrophes autres que les tsunamis se produisent fréquemment dans tout le pays. La reprise après un sinistre est de moins en moins une urgence et de plus en plus une situation chronique. Le grand désastre du Japon de l'Est a été une catastrophe généralisée, soudaine et sans précédent. Des mesures d'urgence ont alors été prises, dont la révision de certains aspects de la législation en matière d'aménagement. Mais aujourd'hui, il est nécessaire d'établir un système de soutien comme un système législatif plus souple et capable de faire face à différents types de reprise post-catastrophe.

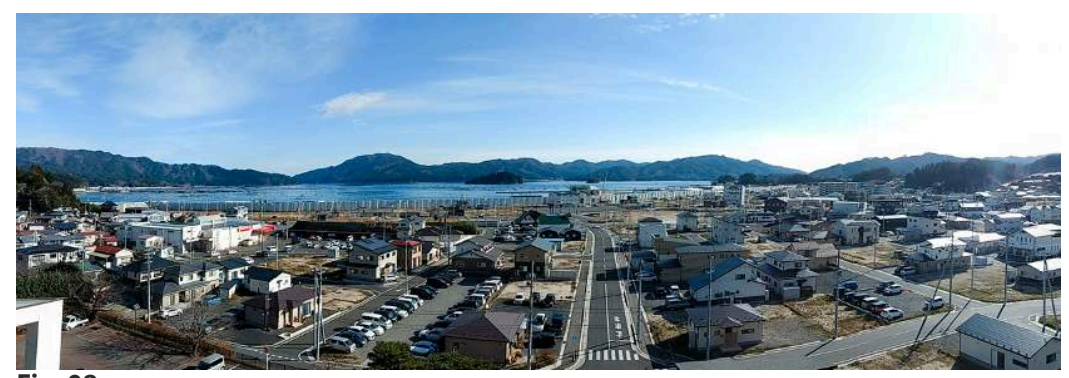

Fig. 08

Le centre-ville de la commune de Yamada (novembre 2020) et les parcelles laissées vides à la suite des opérations de remembrement urbain. 
De plus, même si les surfaces classées en zone urbaine ont augmenté dans le Sanriku par rapport à la situation d'avant-séisme, la population devrait diminuer, pour atteindre, dans 20 ans, $60 \%$ à $70 \%$ du niveau d'avant la catastrophe du 11 mars. Il sera alors difficile pour les communes d'entretenir les nombreuses d'infrastructures issues de la reconstruction. Les infrastructures qui ne seront pas bien entretenues perdront leur fonctionnalité et leur commodité, ce qui entraînera une baisse de l'attractivité de ces zones et accroîtra le déclin démographique. Il est donc nécessaire de trouver des moyens de réduire la charge de l'entretien et de la gestion des équipements aménagés dans le sillage de la reconstruction post-tsunami.

Dans cette optique, il est aussi nécessaire d'évaluer correctement les installations urbaines actuelles en termes d'emplacement, de fonction et d'usage dans une société en décroissance. Il est également nécessaire de réfléchir à la manière d'utiliser les terrains inutilisés pour la prévention et l'atténuation des catastrophes et, dans certains cas, de laisser se réensauvager certaines zones. C'est à dire élaborer des principes et des méthodes de planification basés aussi sur la "soustraction " plutôt que sur l'" addition " permanente de nouveaux aménagements

Une " ville " est un lieu où les individus se rassemblent, interagissent et établissent diverses relations sociales. C'est un lieu où les gens se livrent à une grande variété d'activités, telles que le commerce, la conversation, l'alimentation et la sociabilité autour d'un verre. Même si un espace physique est créé par le développement des infrastructures, cela ne signifie pas nécessairement qu'une "ville» est créée. La reconstruction ne consiste ainsi pas seulement à recréer un espace physique, mais aussi à reconstruire les relations sociales, ou les communautés, qui y prennent place. C'est un des enseignements importants que nous apporte l'analyse de la reconstruction post-tsunami dans la région du Sanriku.

Traduit du japonais par Rémi SCOCCIMARRO. 


\section{Bibliographie}

\section{ABE Toshihiko 阿部俊彦 2017}

« Kesennuma-shi naikō-chiku ni okeru bōchōtei no keikaku to dezain no goi keiseipurosesu » 気仙沼市内湾地区にお ける防潮堤の計画とデザインの合意形成 プロセス (Processus de fabrication du consentement concernant la forme et l'aménagement de la digue antitsunami dans la zone interne du port de la ville de Kesenuma), Publications de la société de Génie civil, D1, 73 (1) : 37-51.

\section{ARAKI Shōko 荒木笙子 \& AKITA Noriko} 秋田典子 2017

«Tsunami hisaichi ni oite fukkō tochi kukakuseiri jigyō ga jūmin no kyojūchi sentaku ni ataeta eikyō : Iwate-ken Kamaishi-shi A-chiku o jirei toshite » 津波被災地において復興土地区画整理事業 が住民の居住地選択に与えた影響一 岩手県釜石市A地区を事例として (Les effets sur les choix de résidence des habitants, des opérations de remembrement urbain des zones concernées par la reconstruction post-catastrophe dans les aires frappées par le tsunami : le cas de la zone A de la ville de Kamaishi dans le département d'Iwate), Revue de la société japonaise d'urbanisme, 52 (3) : 1088-1093.

\section{Hagiwara Takuya 萩原拓也 \& KubotA Aya} 窪田亜矢 2018

«Tsunami jōshū chiiki ni okeru gyogyō shūraku kankyō seibi jigyō ni kan suru kenkyū : heiji no kūkan henyō oyobi higashi Nihon daishinsai go ni okeru fukkō no kūkan seibi to no kankei ni chokumoku shite »津波常 習地域における漁業集落環境整備事業に 関する研究一平時の空間変容及び東日 本大震災後における復興の空間整備との 関係に着目して (Étude sur les travaux d'aménagement du cadre de vie dans les hameaux de pêcheurs des zones régulièrement sujettes aux tsunami : point sur les rapports aux équipements des espaces en reconstruction à la suite du grand désastre du Japon de l'est et les transformations par rapport à la situation antérieure), Revue de la société japonaise d'urbanisme, 50 (3) : 881-888.

\section{HASHIмото Shizuka 橋本禅 2012} "Shinsai fukō to tochiriyō keikaku » 震災復興と土地利用計画 (Planification de I'usage des sols et de la reconstruction post-catastrophe), Revue de la Société d'études rurales, 31 (1) : 37-40.

\section{Kishōchō 気象庁 (Agence} météorologique nationale) 2019 Saigai o motarashita kikō jirei taifudai 19 go ni yoru ōame, hōfū nado 災害を もたらした気象事例 台風第19号による 大雨、暴風等 (Précipitations et vents destructeurs causés par le typhon n ${ }^{\circ} 19$, un cas d'étude d'un phénomène climatique à l'origine de désastres). http://www.data.jma.go.jp/obd/stats/ data/bosai/report/2019/20191012/ jyun_sokuji20191010-1013.pdf (dernière consultation le 28 septembre 2021). 
Kokudo kōtsūshō tōhoku chihō seibi kyoku kamaishikōwan jimusho shiryō 国土交通省東北地方整備局釜石港湾 事務所資料 (Documents du bureau des affaires portuaires de la ville de Kamaishi, Branche de la région du Tōhoku, ministère de l'Aménagement du territoire, des Infrastructures, des Transports et du Tourisme) 2013

Kamaishi-kō fukkyū no torikumi 釜石港復 旧の取り組み (Les efforts de restauration du port de Kamaishi).

\section{Kondō Tamiyo 近藤民代 2015}

«Higashi Nihon daishinsai ni okeru gake chikinsetsu nado kiken jūtaku iten jigyou no katsuyou jittai to kitai sareru yakuwari ni kansuru kisoteki kenkyū : Iwate-ken oyobi Miyagi-ken no hisai jichichai oyobi hisaisha ni taisuru chōsa o tōshite» 東日本大震災におけるがけ地近 接等危険住宅移転事業の活用実態と期待さ れる役割に関する基礎的研究一岩手県およ び宮城県の被災自治体および被災者に対す る調査を通して (Études fondamentales à propos du rôle attendu et de la réalité des opérations de déménagement des habitations en zone dangereuse situé à proximité des reliefs de falaise dans le contexte de la grande catastrophe du Japon de l'Est : aperçu des enquêtes auprès des victime et des collectivité locales touchées par le désastre dans les départements de Miyagi et d'Iwate), Revue de la société japonaise d'architecture, 80 (715) : 2043-2049.

\section{Matsumoto Eri 松本英里 \& UbamURA} Michio 姥浦道生 2015

« Higashi Nihon daishinsai no saigai kikenkuiki no shitei ni kansuru kenkyū »
東日本大震災の災害危険区域の指定に関す 了研究 (Étude à propos de la désignation des zones à risque dans le contexte du grand désastre du Japon de l'Est), Revue de la société japonaise d'urbanisme, 50 (3) : 1273-1280.

MiYAKE Satoshi 三宅諭 2013 «Shūdan iten nado ni okeru jūtaku no iten/saiken o meguru kadai » 集団移 転等による住宅の移転・再建を巡る課題 (Étude concernant la reconstruction et de la relocalisation de l'habitat lors des opérations de relocalisations groupées de zones résidentielles), Revue de la Société d'aménagement rural, 31 (4) : 549-552.

\section{MiYAKe Satoshi 2014}

«Seigyō/kankōgyō no fukkō shien kara tenkai suru shakai kankei shihon »生 業・観光業の復興支援から展開する社会 関係資本 (Le capital social développé à la suite des opérations de soutien à la restauration de la vie quotidienne et de son cadre de vie), Information et savoirs des services de pompiers, 117, été : 23-27.

\section{MiYake Satoshi 2018}

« Kakō to danzetsu o yawarageru keikaku shuhō ron » 過去との断絶を和 らげる計画手法論 (Essai à propos des pratiques de planifications urbaines rendues moins opérantes du fait de l'oubli des expériences passées), Documents pour la conférence de l'année 2018 de la section d'aménagement rural de la Société japonaise d'architecture, branche du Tōhoku : 15-16. 


\section{MiYake Satoshi 2019}

" Higashi Nihon daishinsai kara no fukkō ni okeru itensaki jūtakuchi no keikaku henka ni kansuru kenkyū »

東日本大震災からの復興における移 転先住宅地の計画変化に関する研究 (Étude concernant la transformation de l'aménagement urbain des zones résidentielles relocalisées dans le cadre de la reconstruction post-catastrophe à l'issue du Grand désastre du Japon de l'Est), Revue de la société japonaise d'urbanisme, 54 (3) : 1116-1122.

\section{MiYAKe Satoshi \& ŌTAKI Hidemoto} 大瀧英知 2018

« Iwate-ken Noda-mura no fukkō machizukuri ni okeru shōchūkō sanka ni yoru toshi kōen jigyō no sōkatsu » 岩手県野田村の復興まちづく りにおける小中高参加による都市公園 事業の総括 (Synthèse des opérations d'aménagement d'un parc urbain dont les élèves de primaire, collège et lycée ont participé à l'élaboration, dans le cadre de l'urbanisme collaboratif de reconstruction post-catastrophe du village de Noda, dans le département d'Iwate), Revue de la société japonaise d'urbanisme, 53 (3) : 445-452.

\section{Naimu daijin kanbō toshikeikakuka 内務大臣官房都市計画課 (Section de I'aménagement urbain, bureau du ministère des Affaires intérieures) 1934 Sanriku ni yoru higai chōson no fukkō keikaku hōkokusho 三陸津浪に因る被 害町村の復興計画報告書 (Rapport sur l'aménagement post-catastrophe des bourgs et villages endommagés par le tsunami du Sanriku).}

Onoda Yasuaki 小野田泰明, Katō Yuichi 加藤優一 \& TsukUdA Haruka 佃悠 2015 «Saigai fukkō jigyō ni okeru keikaku jissō to jichitai no soshiki taisei : higashi Nihon daishinsai ni okeru Miyagi-ken no fukkō jigyō o taishō toshite » 災害 復興事業における計画実装と自治体の 組織体制一東日本大震災における宮城 県の復興事業を対象として (Structure institutionnelle des collectivités locales et dotation d'équipements dans le cadre des travaux de reconstruction postcatastrophe : le point sur les opérations de reconstruction post catastrophe dans le département de Miyagi après le Grand désastre du Japon de l'Est), Revue de la société japonaise d'Architecture, 80 (717) : 2523-2531.

\section{SATō Takao 佐藤隆雄 2012}

«Tsunami saigai gyoson no fukkō keikaku/jigyō kara mietekita kadai to kongo no arikata » 津波災害漁村の復 興計画·事業から見えてきた課題と今後 のあり方 (Le cas présent et à venir de ce que l'on peut observer des travaux d'aménagement et de reconstruction dans les villages de pêcheurs frappés par le tsunami), Revue de la Société d'études rurales, 31 (1) : 26-32.

\section{Sonoda Chika 園田千佳, SAKAMOto Keisuke 坂本慧介 \& IsHIKAWA Mikiko 石川幹子 2013 \\ «Fukkō machizukuri no keikaku sakutei purosesu ni okeru jūmin wākushoppu no yakuwari ni kansuru kenkyū : Miyagi-ken Iwanuma-shi ni okeru fukkō machizukuri o tōshite » 復興まちづくりの 計画策定プロセスにおける住民 ワークショップの役割に関する研究一宮城県}


岩沼市における復興まちづくりを通

して (Étude sur le rôle des ateliers participatifs avec les habitants dans les processus décisionnels lors des opérations d'urbanisme collaboratifs pour la reconstruction post-

catastrophe : aperçus de l'urbanisme collaboratif de reconstruction postcatastrophe dans la ville d'Iwanuma, département de Miyagi), Revue de la société japonaise d'urbanisme, 48 (3) : 849-854.

Tōkyō suisan shinkō kai 東京水産振興会 (Association pour la promotion de la pêche de Tokyo) 2018

Higashi Nihon daishinsai ni okeru gyoson fukkō no mondai : Heisei 29 nen jigyō hōkokusho 東日本大震災における漁村 復興の問題一平成29年度事業報告書 (La question de la reconstruction des villages de pêcheurs à la suite du Grand désastre du Japon de l'Est : rapport d'activité pour l'année 2017).

\section{Tōkyō suisan shinkō kai 2019}

Higashi Nihon daishinsai ni okeru gyoson fukkō no mondai : Heisei 30 nen jigyō hōkokusho 東日本大震災における漁村 復興の問題一平成30年度事業報告書 (La question de la reconstruction des villages de pêcheurs à la suite du Grand désastre du Japon de l'Est : rapport d'activité pour l'année 2018).
Un.yūshō daini kōwan kensetsu kyoku miyakokō kōji jimusho 運輸省第二港 湾建設局宮古港工事事務所 (Bureau des travaux publics du port de Miyako, département de la construction des ports de rang 2 du ministère des Transports) 1986

Miyako-kō kōji jimusho 30 nen shi 宮古港 工事事務所30年誌 (Publication pour les 30 ans du bureau des travaux publics du port de Miyako).

Yamanaka Shintarō 山中新太郎, Satō Mitsuhiko 佐藤光彦 \& Fuлммото Yōsuke 藤本陽介 2018

« Gyoson shūraku ni okeru hisai setai no kyojūchi saiken ikō to ricchisei : higashi Nihon daishinsai ni okeru Miyagi-ken Ishinomaki-shi Ogatsu-chiku no fukkō o taishō toshite » 漁村集落における被災 世帯の居住地再建意向と立地生一東日本 大震災における宮城県石巻市雄勝地区の 復興を対象として (Localisation et choix de reconstruction de l'habitat au sein des foyers victimes de la catastrophe du 11 mars dans les hameaux de pêcheurs : le point sur la reconstruction postcatastrophe dans le district d'Ogatsu, ville d'Ishinomaki, département d'Iwate, après le Grand désastre du Japon de I'Est), Revue de la société japonaise d'architecture, 83 (745) : 405-415.

\section{YAMASHITA Fumio 山下文男 2008}

Tsunami tendenko 津波てんでんこ (Tsunami! Sauve qui peut, chacun pour soi), Tokyo, Shin Nihon shuppansha 新日本出版社 : 101-103. 
